\title{
A New Method for Analyzing Near-Field Faraday Probe Data in Hall Thrusters
}

\author{
Wensheng Huang ${ }^{*}$, Rohit Shastry ${ }^{\dagger}$, Daniel A. Herman ${ }^{\ddagger}$, George C. Soulas ${ }^{\S}$, and Hani Kamhawi ${ }^{* *}$ \\ National Aeronautics and Space Administration Glenn Research Center, Cleveland, Ohio, 44135
}

\begin{abstract}
This paper presents a new method for analyzing near-field Faraday probe data obtained from Hall thrusters. Traditional methods spawned from far-field Faraday probe analysis rely on assumptions that are not applicable to near-field Faraday probe data. In particular, arbitrary choices for the point of origin and limits of integration have made interpretation of the results difficult. The new method, called iterative pathfinding, uses the evolution of the near-field plume with distance to provide feedback for determining the location of the point of origin. Although still susceptible to the choice of integration limits, this method presents a systematic approach to determining the origin point for calculating the divergence angle. The iterative pathfinding method is applied to near-field Faraday probe data taken in a previous study from the NASA-300M and NASA-457Mv2 Hall thrusters. Since these two thrusters use centrally mounted cathodes, the current density associated with the cathode plume is removed before applying iterative pathfinding. A procedure is presented for removing the cathode plume. The results of the analysis are compared to far-field probe analysis results. This paper ends with checks on the validity of the new method and discussions on the implications of the results.
\end{abstract}

\begin{tabular}{llll}
\multicolumn{4}{c}{ Abbreviations } \\
GRC & $=$ Glenn Research Center & $\mathrm{CEX}$ & $=$ Charge Exchange \\
$300 \mathrm{M}$ & $=$ NASA-300M & $\mathrm{SEE}$ & $=$ Secondary Electron Emission \\
$457 \mathrm{Mv} 2$ & $=$ NASA-457Mv2 & $\mathrm{CD}$ & $=$ Current Density \\
HARP & $=$ High-speed Axial Reciprocating Probe & &
\end{tabular}

\section{Introduction}

R ECENTLY, Hall thrusters have been seeing a rise in popularity as primary spacecraft propulsion in the United States. Examples include the use of Busek's 200-W Hall thruster on TacSat-2, ${ }^{1}$ the use of Aerojet's BPT-4000 Hall thrusters ${ }^{2}$ on the Air Force Advanced Extremely High Frequency satellite program, and NASA mission concepts that use high power Hall thrusters to reduce the cost of a manned trip to Mars. ${ }^{3,4}$ While the community understands the physics and engineering of the Hall thruster well enough to develop flight units, there are still many gaps in that understanding. One of those knowledge gaps relates to the transition of Hall thruster plasma plume from the well-defined annular jet at the thruster exit to the diffused plume in the far-field.

To improve understanding of plume transition in a Hall thruster, one approach is to insert electrostatic probes into the plume and interrogate for local plasma properties. However, the plasma in the near-field of a Hall thruster is highly energetic and will cause stationary probes to overheat, possibly to the point of probe failure. In 2000, Haas, et al., pioneered the use of a high-speed axial reciprocating probe (HARP) system to overcome the heating issue by rapidly inserting and retracting probes into and out of the near-field region of a Hall thruster. ${ }^{5}$ Since then, many new tests involving various electrostatic probes have been performed using the same concepts and methods. ${ }^{6-12}$ This paper will focus specifically on the development of the near-field Faraday probe. A Faraday probe is a flat metal

\footnotetext{
${ }^{*}$ Research Engineer, Propulsion and Propellants, wensheng.huang@nasa.gov, AIAA Member.

${ }^{\dagger}$ Research Engineer, Propulsion and Propellants, rohit.shastry@nasa.gov, AIAA Member.

* Research Engineer, Propulsion and Propellants, daniel.a.herman@nasa.gov, AIAA Senior Member.

$\S$ Research Engineer, Propulsion and Propellants, george.c.soulas@nasa.gov, AIAA Member.

${ }^{* *}$ Research Engineer, Propulsion and Propellants, hani.kamhawi-1@nasa.gov, AIAA Associate Fellow.
} 
disk, sometimes with a guard ring, that is biased well into ion saturation regime of the local plasma in order to measure the ion current density. Analysis of the ion current density as a function of position can yield information on total ion beam current and plume divergence.

Currently, the biggest obstacle associated with using the near-field Faraday probe is the ad-hoc nature of the existing data analysis methods. There are two outstanding issues with existing analysis methods. One, existing methods typically start with assumptions about the point of origin from which the near-field plasma emanates. These assumptions are not grounded in physics or plasma properties but on thruster geometry. Two, the analysis results are often strongly tied to the integration limits, which are necessary due to the otherwise infinite nature of the integration domain.

A new data analysis method, called iterative pathfinding, is presented in this paper. This new method is an attempt to address the first of the aforementioned issues. The general principle of the iterative pathfinding method can be summarized in two steps. Step one, using a guess on the point of origin and the divergence equation, the direction and spread in the plasma plume is calculated. Step two, data on the evolution of the direction and spread in the plume with distance is fed into an algorithm to find a new guess on the point of origin. Steps one and two are repeated until convergence is achieved. In order to establish the error metrics for evaluating the next guess on the location of the point of origin, an assumption on how the near-field plasma evolves with distance is needed. For this study, the near-field plasma plume is assumed to undergo free-expansion, with no self-interaction, after exiting the channels of the Hall thruster. No assumption is made on the angular distribution of the plasma plume. While the new method is still sensitive to the choice of integration limits, the resulting origin points are physics- and plasma property-based. Validity of the new method is evaluated by assessing the sensitivity of the results to integration limits and comparing said results to those obtained from a far-field Faraday probe.

\section{Past Work}

In 2000, Haas, et al., pioneered the use of electrostatic probes in the near-field of the Hall thruster by developing a technical solution to the problem of near-field probe heating. ${ }^{5}$ Shortly after, in 2003, Hofer and Gallimore used this technical solution with a near-field Faraday probe to map the near-field ion current density of the NASA-173Mv2. ${ }^{7}$ Being the first near-field Faraday probe study, the authors did not have time to fully explore multiple operating conditions and bias voltages. No divergence analysis was performed and total beam current was calculated at one axial distance.

After the pioneering days, near-field Faraday probe studies did not surface again in the literature until 2008, when Jameson ${ }^{9}$ and Reid ${ }^{8}$ independently applied it to two separate H6 Hall thrusters. Jameson used the near-field Faraday probe data to calculate total beam current at one axial distance and relied on far-field Faraday probe data for divergence calculation. Reid proposed a method for measuring the spread in the plume so that comparison can be made across different operating conditions. Reid also tried several different schemes for determining the integration limits.

Since then, three more near-field Faraday probe studies have been published including the 2011 work by Shastry on an H6 Hall thruster, ${ }^{13}$ the 2012 work by Hofer, et al., on the H6MS, ${ }^{14}$ and the 2012 work by Huang, et al., on the NASA-300M and NASA-457Mv2. ${ }^{11}$ The 2011 work by Shastry followed the methodology outlined in Reid's 2008 work. The 2012 work by Hofer, et al., was focused on the application of magnetic shielding to the H6 Hall thruster and did not describe the near-field Faraday probe analysis in detail.

The 2012 work by Huang, et al., on the NASA-300M and NASA-457Mv2 proposed a new physics-based data analysis method that borrowed a few concepts from optical ray tracing. ${ }^{11}$ The authors noted that the near-field current density profiles in the vicinity of the discharge channel have Gaussian-like distributions. They assumed that the near-field plasma plume can be approximated as free-expanding Gaussian jets, similar to free-expanding Gaussian beam in laser beam physics. In laser beam physics, the spatial extent of the beam is well-defined by the location where the beam intensity drops to $1 / \mathrm{e}^{\mathrm{n}}$ of the peak intensity, where $\mathrm{n}$ is usually 2 . Connecting these locations as a function of axial distance for various values of $\mathrm{n}$ creates a form of ray tracing where all the rays lead back to the effective point of origin for the beam. While the method was interesting, difficulties related to analyzing the plume near the central axis of the thruster where the cathode plume dominates put some of the results into question.

Having listed known near-field Faraday probe studies on the Hall thruster, this paper will now turn to how data analysis had been carried out in these studies. The focus in this section will be on how the point of origin and limits of integration are determined.

The current density is a scalar value and the direction of the local ions cannot be determined from the current density. To calculate divergence angle from current density data, one must know where said current originates from. 
Of the mentioned prior studies that attempted to determine the divergence angle from near-field Faraday probe data, two studies ${ }^{8,13}$ assumed the point of origin is located along the centerline of the discharge channel at the channel exit plane. This assumption is invalid because interior probing has already revealed that the acceleration zone of the Hall thruster is located near the exit plane and has a non-negligible spatial extent from the perspective of the near-field region. ${ }^{15}$ Or in other words, if one assumes the plasma originates from the intersection between the discharge channel centerline and the exit plane, then one cannot also assume that the source is a singular point. The only study that used plasma properties to determine the point of origin was only able to analyze the plasma occupying radial positions greater than the channel centerline. ${ }^{11}$ As such, there is currently no proven method for finding the point of origin and is likely the reason why near-field Faraday probe data is generally not used to calculate plume divergence. Nevertheless, studying how the annular plasma jet from the Hall thruster transition from the near-field to the far-field requires an understanding of the direction and spread of said plasma jet.

At this point in the paper, it is beneficial to discuss why near-field Faraday probe analysis generally requires some form of integration limits. Far-field Faraday probe study, the pre-cursor to near-field Faraday probe study, is usually carried out by sweeping the probe in a semi-circle around the thruster through the central axis of the thruster, also called a polar sweep. When swept this way, the surface normal vector for the collector of the probe is always pointed at the Hall thruster. Integration can then be carried out from $-90^{\circ}$ to $+90^{\circ}$ with the assumption that any ions collect beyond those angles are going the wrong way for thrust generation and likely a result of charge-exchange reaction. Further details on how to carry out a far-field Faraday probe study and deal with the effect of chargeexchange reaction can be found in Brown's works. ${ }^{16,17}$ A near-field Faraday probe cannot be swept in the same fashion as a far-field Faraday probe. Since most Hall thrusters have relatively flat faces, sweeping in the near-field is generally carried out either radially or axially in a rectangular coordinate system. Equation (1) shows the mathematical definition of the cosine of the divergence angle for a polarly-swept probe.

$$
<\cos \delta>_{j}=\frac{2 \pi R^{2} \int_{0}^{\pi / 2} j(\theta) \cos \theta \sin \theta d \theta}{2 \pi R^{2} \int_{0}^{\pi / 2} j(\theta) \sin \theta d \theta}
$$

Where $\mathrm{R}$ is the distance from the thruster to the probe, $\mathrm{j}$ is the current density, and $\theta$ is the polar angle defined as equal to 0 when pointed along the central axis of the thruster. Note the denominator of Eq. (1) is equal to the integrated beam current. For a radially swept probe where the pointing direction of the probe is fixed, the equation for the cosine of the divergence angle becomes Eq. (2).

$$
<\cos \delta>_{j}=\frac{2 \pi \int_{0}^{\infty} j_{z}(r) \cos \theta r d r}{2 \pi \int_{0}^{\infty} j_{z}(r) r d r}, \cos \theta=\frac{z-z_{p}}{\sqrt{r^{2}+\left(z-z_{p}\right)^{2}}}
$$

Where $\mathrm{j}_{\mathrm{z}}$ has the subscript $\mathrm{z}$ to denote the fact that the probe is always pointed in the axial direction, $\mathrm{r}$ is the radial coordinate, $z_{p}$ is the axial position of the point of origin. Radial position of the point of origin is assumed to be 0 . Polar sweeping of a near-field Faraday probe is not done because the probe cannot get as close to the thruster exit plane as in the case of rectangular sweeping and cannot be made to always face the local plasma (origin can no longer be treated as one point). Comparing Eq. (2) to Eq. (1) it becomes clear that while polarly-swept data is integrated from 0 to a finite number, radially-swept data is integrated from 0 to infinity.

Aside from the mathematical issues associated with integration to infinity, two other experimental effects complicate the integration of radially-swept probe data. One, charge-exchanged (CEX) ions associated with a nonzero background pressure (separate from CEX ions associated with thruster neutrals) adds current to the measurement of a Faraday probe. At large values of $r$, the integration area is sufficiently large that even small CEX current can contribute to large total integrated current, even though this CEX current is not a part of the beam current. Reid's work showed that integration of the current density from 0 to the limit of the data set often generate a total beam current that exceeded the discharge current, which is unphysical. ${ }^{8}$ Two, noise and systematic offset in the data acquisition circuit can become greatly amplified when integrated to large values of radial position. To counter these undesirable effects, some kind of integration limits is generally necessary. 
Of the prior studies mentioned in this section, all but two studies used some scheme to determine the proper limits of integration when integrating for the total beam current. The two studies that are exceptions tried to subtract out the influence of the cathode plume, if applicable, and CEX ions, then integrated up to the limit of the measurement domain. ${ }^{7,14}$ No detail is given on how the cathode plume is removed. ${ }^{14}$ CEX ions were assumed to add a fixed amount of current density regardless of position and subtracted out. However, the production rate of CEX ions is known to depend on ion density, neutral density, ion energy, and distance from the thruster. The assumption of a constant CEX floor is questionable. In the remaining studies, the schemes for determining the limits of the integration can be divided into two categories, discharge channel integration and threshold-based limits (a.k.a. dynamic window integration). Discharge channel integration ${ }^{8,9}$ uses the radial positions of the inner and outer discharge channel walls as the lower and upper integration limits, respectively. Reid finds that discharge channel integration is only meaningful when the data is extremely close to the exit plane, ${ }^{8}$ where plasma potential data indicates that some acceleration is still occurring. ${ }^{15}$ Threshold-based limits ${ }^{8,11,13}$ define the integration limits as the radial positions where the current density has dropped to some fraction of the peak current density. For traces with noticeable cathode plume, care must be taken during implementation to ensure the peak current density is that of the beam ions. For a free-expanding plasma jet, threshold-based limits will always bound the same amount of current density at every axial position and is the closest scheme to a physics-based scheme out of all those proposed for determining integration limits. Threshold-based limits also scales very well from one thruster to another as the absolute value of the threshold scales with peak current density, which is assumed to scale with discharge current. Nevertheless, the scheme of threshold-based limits has one major weakness; how one chooses the correct value of the fraction that determines the threshold is unclear. One possible approach is to calibrate the near-field Faraday probe results using far-field Faraday probe results.

Proper choice of the integration limits is an ongoing area of research and is not resolved by the new analysis method. The authors believe more data is necessary to satisfactorily resolve this issue.

\section{The New Method}

The following sections describe the various steps in the new near-field Faraday probe analysis method. To better illustrate the process, near-field Faraday probe data taken from the NASA-300M operating at $500 \mathrm{~V}$ discharge voltage and $20 \mathrm{~kW}$ discharge power is used as an example. Detailed description of the experimental setup and nearfield Faraday probe testing of the NASA-300M can be found in a previous work. ${ }^{11}$ All Hall thruster operating conditions are labeled as www $\mathrm{V}$, yy $\mathrm{kW}$, where www is the discharge voltage in volts and yy is the discharge power in kilowatt. All data presented are plotted on spatial coordinates that have been normalized by the mean channel diameter of the associated Hall thruster. $\mathrm{R}$ is the normalized radial coordinate and is 0 at the central axis of the thruster. $\mathrm{R}$ is positive traveling towards the 3 o'clock position of the thruster when the thruster is viewed face-on. $\mathrm{Z}$ is the normalized axial coordinate and is 0 at the thruster channel exit plane. $\mathrm{Z}$ is positive traveling downstream of the exit plane. Mean channel diameter is the average of the inner and outer discharge channel wall diameters. Thus, the centerlines of the discharge channels correspond to $\mathrm{R}= \pm 0.5$.

Note that for the purpose of this paper, only the near-field plasma upstream of plume merging is referred to as jets because they tend to be well-defined in spatial extent in the near-field close to the exit plane.

\section{A. Cathode Plume Removal}

Before applying the new near-field Faraday probe analysis method, the cathode plume needs to be treated. For data sets taken on Hall thrusters with centrally mounted cathodes, like the sets that will be shown later, the cathodes produced dense plasmas in the near-field that was recorded by the Faraday probe. Ions in the cathode plume are not beam ions and must be excluded from the divergence and beam current calculations. For the purpose of this study, the cathode plume is assumed to be an expanding jet that does not interact with itself or the beam plasma. However, the plume is allowed to be stretched slightly in the radial direction by any electric and magnetic fields present. The exact form that best fit the cathode plume is unknown so several different forms were tried.

Since the cathode plume is known to interact with the beam plume at some downstream distance (Hall thruster operation require electrons from the cathode to mix with the beam plasma), the aforementioned assumption is only applicable for cathode plume very close to the exit plane. One must define a domain over which the cathode plume is curve-fitted. After performing analysis on the data from the $300 \mathrm{M}$ and $457 \mathrm{Mv} 2$ at many operating conditions, the integrated current from the region near the cathode was observed to rise as one traveled downstream. This trend is presumably due to increases in the mixing and interaction of the cathode plume with the beam plume. Another possibility is that the increased current is from a phenomenon known as the "central spike" observed in many other Hall thruster studies (including ones without a centrally-mounted cathode) ${ }^{7,8}$ At this point, the nature of this rise in 


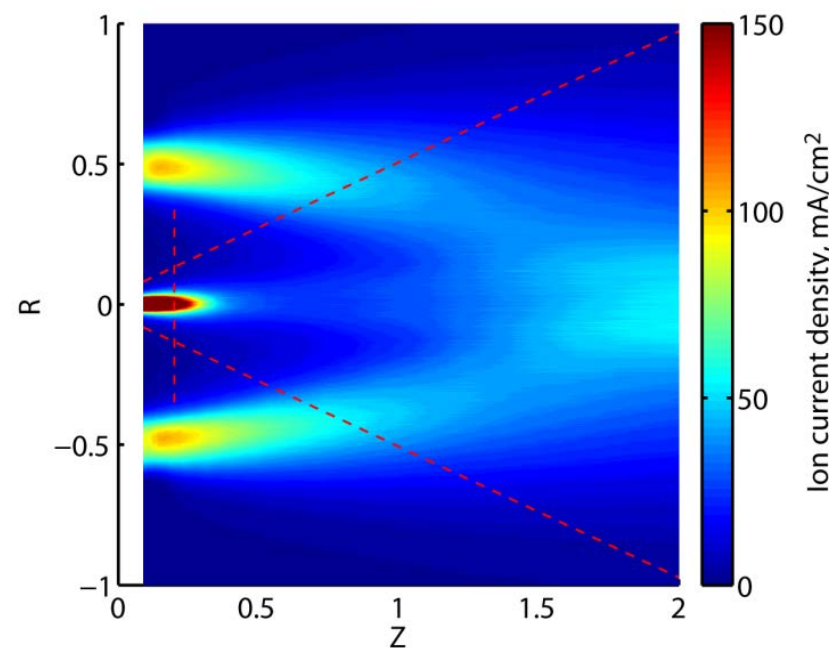

Figure 1. Flooded current density contour with dashed boundary lines showing the cathode curve-fit domain. (300M operating at $500 \mathrm{~V}, 20 \mathrm{~kW})$

The radial boundaries for the curve-fit domain were chosen captured most of the cathode plume but almost no beam plume, the curve-fitting results would be accurate. The radial boundaries are chosen to be a pair of lines radiating outward at $\pm 25^{\circ}$ from the orifice of the cathode plus a bit of extra space corresponding to twice the orifice diameter. Figure 1 shows the flooded current density contour for the $300 \mathrm{M}$ operating at $500 \mathrm{~V}, 20 \mathrm{~kW}$. Overlaid on the figure are red dashed lines showing the boundaries of the cathode curve-fit region.

Curve-fitting was performed on each of the Faraday probe sweeps that fell within the cathode curve-fit domain. Curve-fit forms that were tried include the Gaussian, the variable exponential, and the twin Gaussian. The authors quickly discovered that the Gaussian form left behind too much plume near the base of the cathode plume. The twin Gaussian form fitted well but used too many variables. The width of the twin Gaussian form was difficult to define since it involves two overlapping Gaussians. Same was also true of the variable exponential form. However, after performing curve-fits on the data from the $300 \mathrm{M}$ and $457 \mathrm{Mv} 2$ at many operating conditions, the authors noticed the power on the variable exponential form fell somewhere between 0.6 and 1.2 for all fitted traces with an average roughly around 0.9 . The analysis program is capable of handling a power of 0.9 but for the sake simplicity and to make analytic checks possible a power of 1 was used instead. Thus, the best fit form for the cathode plume in the region very close to the exit plane was found to be a simple exponential decay function. Equations (3) to (6) show the mathematical expressions for the various curve-fit forms used.

$$
\begin{aligned}
\text { Exponential decay: } & \mathrm{f}(\mathrm{r})=\mathrm{A} * \exp [-|\mathrm{r}| / \mathrm{B}] \\
\text { Gaussian: } & \mathrm{f}(\mathrm{r})=\mathrm{A} * \exp \left[-\mathrm{r}^{2} / \mathrm{B}\right] \\
\text { Variable Exponent: } & \mathrm{f}(\mathrm{r})=\mathrm{A} * \exp \left[-|\mathrm{r}|^{\mathrm{n}} / \mathrm{B}\right] \\
\text { Twin Gaussian: } & \mathrm{f}(\mathrm{r})=\mathrm{A}_{1} * \exp \left[-\mathrm{r}^{2} / \mathrm{B}_{1}\right]+\mathrm{A}_{2} * \exp \left[-\mathrm{r}^{2} / \mathrm{B}_{2}\right]
\end{aligned}
$$

Where $\mathrm{A}, \mathrm{B}, \mathrm{n}, \mathrm{A}_{1}, \mathrm{~B}_{1}, \mathrm{~A}_{2}$, and $\mathrm{B}_{2}$ are fitting constants.

Figure 2 shows an example of curve-fitting the Gaussian form to the cathode plume. Note the bump near the base of the cathode plume in the left-over trace (blue solid line, grey when printed in black and white).

Once curve-fit has been performed on the near-field plume close to the exit plane, the cathode plume was extrapolated downstream to the rest of the measurement domain. To perform this extrapolation, an overall curve-fit was found that adequately describe the individual curve-fit result. In particular, the width parameter, B, was plotted against the normalized axial coordinate, $Z$, and fitted to a second-order polynomial. For a free-expanding jet under no external force, the plot of $B$ versus $Z$ will form a straight line. By using a second-order polynomial, the jet was allowed to have some perturbation in the radial direction that could result from influence by external electric and magnetic forces. The integrated current of the cathode plume was also calculated and averaged over the curve-fit 
domain. Using the result of the polynomial fit of $\mathrm{B}$ versus $\mathrm{Z}$ and the average integrated cathode current, the fitting parameter A was re-calculated for the entire measurement domain. This step effectively re-normalized the equations fitted to the cathode plume so that the integrated cathode current was constant for all axial positions. The resulting overall fit follows the original assumption that the cathode plume is an expanding jet that does not interact with itself or the beam plasma.

Figure 3 shows examples of curve-fitting the exponential decay form to the cathode plume at various axial positions. The black lines show the data and the red dashed lines show the curve-fit results. Note that sometimes the cathode current density was so high that the data acquisition system saturated (this occurred at $\sim 380 \mathrm{~mA} / \mathrm{cm}^{2}$ for the data set shown). When this occurred, the data analysis program excluded the saturated region while performing the curve-fit. Since the curve-fit result can be much higher than the raw data in the saturated region, subsequent subtraction of the curve-fit result from the raw data can cause artificial negative data to be introduced. The program resolves this issue by zeroing out any negative value within the saturated region after the subtraction is performed.
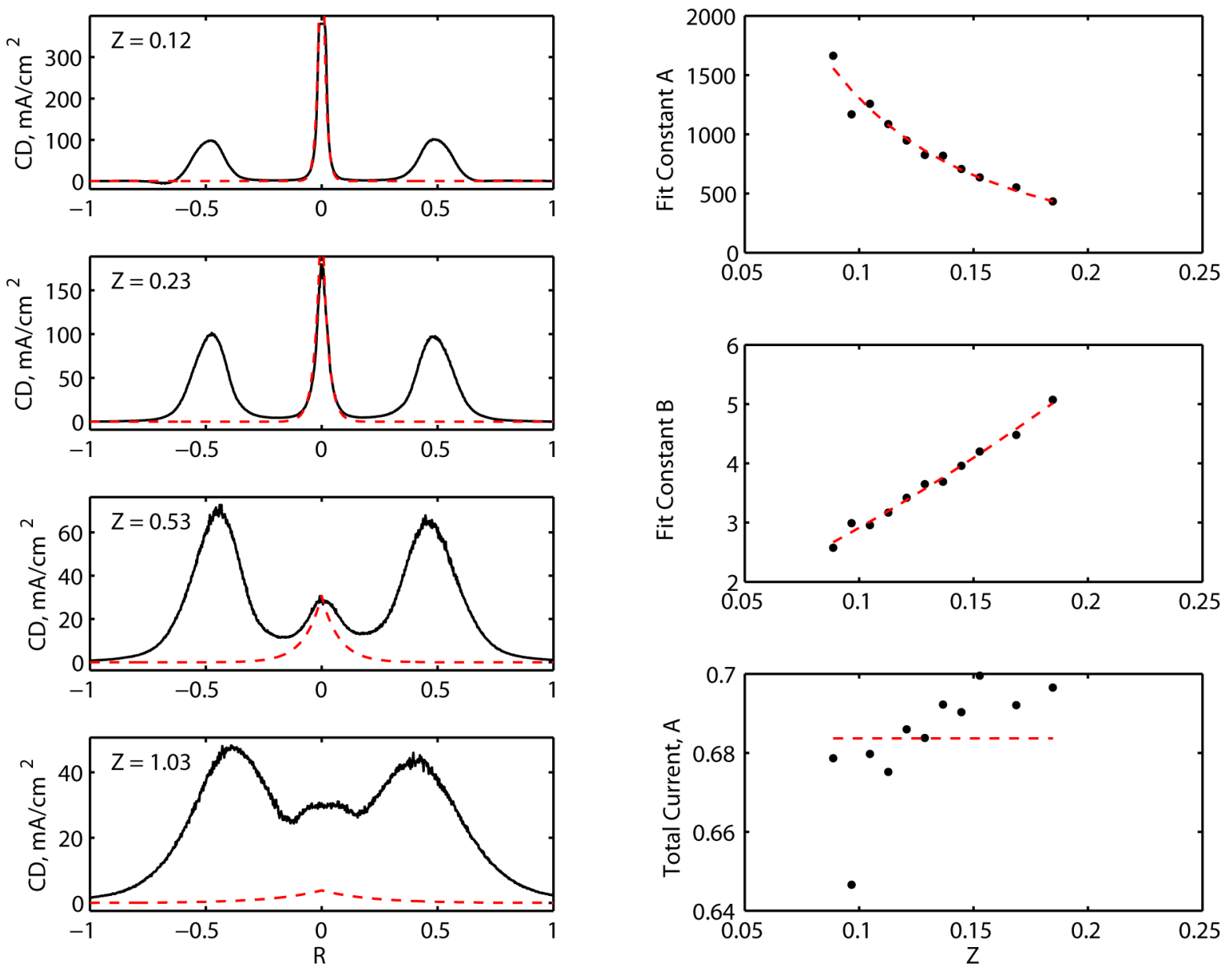

Figure 3. Examples of curve-fitting the exponential Figure 4. The curve-fit parameters A, B, and the decay form to the cathode plume at various axial positions. (300M operating at $500 \mathrm{~V}, 20 \mathrm{~kW})$

Black solid lines indicate the raw trace. Red dashed lines indicate the curve-fit results. CD stands for current density. integrated cathode current as a function of axial position.

Black dots indicate curve-fit results. Red dashed lines indicate the overall fit that will be used to project the cathode plume beyond the curve-fit domain.

Figure 4 shows the curve-fit parameters A, B, and the integrated cathode current as a function of axial position. The black dots are the curve-fit results within the cathode curve-fit domain $(Z<0.2)$. The red dashed lines show the overall curve-fit that will be used to extrapolate the influence of the cathode throughout the measurement domain. The middle plot shows the second order polynomial fit of B vs Z. The lower plot shows the total cathode current at each $\mathrm{Z}$ position as well as the average over the entire cathode curve-fit domain. The upper plot shows the fit constant 
A from the curve-fit and from the normalization calculation. The upper plot is effectively a check on the overall curve-fit results.

Having found an overall curve-fit to the cathode plume, the cathode plume curve-fit was subtracted from the raw data, which sometimes generated odd looking spikes. This was often due to the slight mis-alignment between the raw data and the curve-fit results. To make sure these spurious spikes do not affect the analysis results, an additional section of code is added to exclude these spikes from the next step of the analysis. This section of code looks for the local minima between the spike and the rest of the plasma plume and limits the integration boundary appropriately. The effectiveness of this section of code can be seen in a later contour plot with the integration limits overlaid. Figure 5 shows an example of applying the overall cathode plume curve-fit at one axial distance. Note the line representing the left-over trace contains one spurious spike.

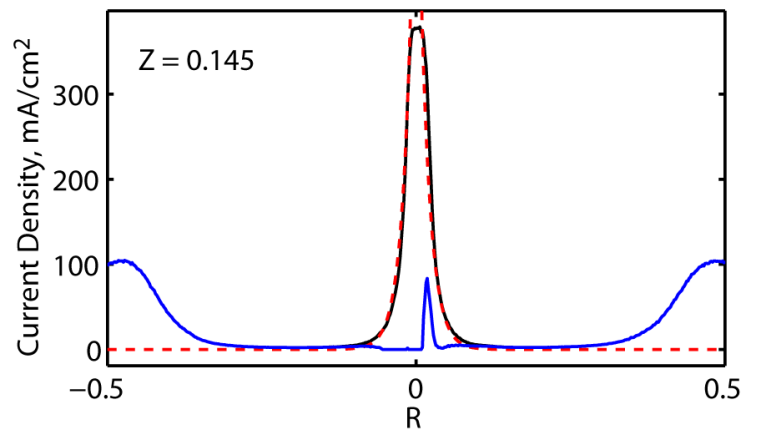

Figure 5. Curve-fitting the exponential decay form to the cathode plume. $(300 \mathrm{M}$ operating at $500 \mathrm{~V}$, $20 \mathrm{~kW}$ )

\section{B. The Iterative Pathfinding Method}

Since real experimental data is accompanied by noise, the problem of fitting the path of a plasma jet to said data is mathematically overdetermined. There is more than one solution to the problem and none of them fits perfectly. To find the best fit solution, a relatively simple and fast approach is to establish error metrics and minimize the error iteratively. The iterative pathfinding method starts with one simplifying assumption, which is easiest to understand from a 2D axisymmetric view (a cross-section view of the Hall thruster). In this view, the annular plasma jet show up as two jets, one on the $+\mathrm{R}$ side and one on the $-\mathrm{R}$ side, and are the mirror image of each other. The iterative pathfinding method assumes that each of the two plasma jets can be approximated as originating from a single point. The point becomes a ring in a $3 \mathrm{D}$ view. No assumption is made about the angular distribution of the current density (i.e. the current density does not have to have a Gaussian

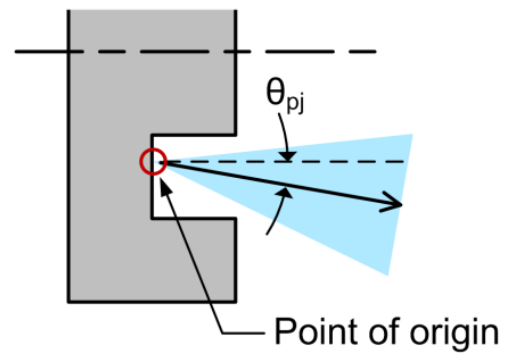

Figure 6. Illustration of a freeexpanding jet emanating from a point in $2 \mathrm{D}$ axisymmetric space. distribution). Figure 6 illustrates this assumption. The plasma jets are assumed to expand freely beyond the channel exit plane at some angle, called the travel angle, and have some effective jet divergence angle. Within this paper, $\theta_{\mathrm{pj}}$ stands for the jet travel angle on the $+\mathrm{R}$ side, $\theta_{\mathrm{nj}}$ stands for the jet travel angle on the $-\mathrm{R}$ side, $\delta_{\mathrm{pj}}$ stands for the divergence angle of the jet on the $+\mathrm{R}$ side, and $\delta_{\mathrm{nj}}$ stands for the divergence angle of the jet on the $-\mathrm{R}$ side. Travel angles are defined as 0 when pointed axially and positive when leaning towards the $+R$ direction. Thus, a jet on the positive side with a positive travel angle and a jet on the negative side with a negative travel angle are both pointing radially outward.

For a free-expanding jet, both the travel angle and the divergence angle are constant as the jet expands but only if the calculation is carried out using the true point of origin. If one carries out the calculation using a different point as the origin, the travel and divergence angles will appear to vary with axial position. One can build an error metric out of the variations in the travel and divergence angles and try out different origin locations until the error is minimized. For example, if the guess origin location is higher up in the drawing than the red circle in Fig. 6, the upstream part of the blue jet will appear to have a large positive travel angle while the travel angle of the downstream jet will appear to be small. One can then move the guess origin location downward until the travel angle calculated at different axial positions agree. On the other hand, if the guess origin location is somewhere along the solid black travel arrow but to the left or right of the red circle, the travel angles along the entire jet will appear to be the same, but the divergence angles will not. One can then move the guess origin location along the travel axis until the divergence angles calculated at different axial positions agree.

In the actual implementation of the iterative pathfinding method there are two core steps. In step one, starting with a guess on the point of origin, the travel and divergence angles are calculated over various axial positions. Since the jet from the $+\mathrm{R}$ and $-\mathrm{R}$ sides are expected to eventually merge, the free-expanding jet assumption is only good in the near-field. In fact, a good way to define the near-field region is the axial extent over which there is no jet merging. Analysis of the $300 \mathrm{M}$ and $457 \mathrm{Mv} 2$ data at many operating conditions show that the jets can start merging as early as $Z=0.5$ depending on the discharge voltage (lower discharge voltage generally trends with earlier 
merging). The authors also noticed the values of the angles and total integrated current tend not to be very stable in the very near-field, typically $Z<0.2$. This effect can be seen in later plots. The jet analysis zone (separate from the cathode curve-fit zone) is defined as $0.2<\mathrm{Z}<0.5$ based on the preceding observations. Equation (7) is the integral equation for calculating the travel angle. Integration limits were replaced with appropriate limits to be described in a later section. Mirroring these limits to the $-\mathrm{R}$ side gives the equation for $\theta_{\mathrm{nj}}$.

$$
\tan \theta_{\mathrm{pj}}=\frac{2 \pi \int_{0}^{\infty} \mathrm{j}_{\mathrm{z}}(\mathrm{r}) \tan \theta \mathrm{rdr}}{2 \pi \int_{0}^{\infty} \mathrm{j}_{\mathrm{Z}}(\mathrm{r}) \mathrm{rdr}}, \tan \theta=\frac{\mathrm{r}-\mathrm{r}_{\mathrm{p}}}{\mathrm{z}-\mathrm{z}_{\mathrm{p}}}
$$

Where $r_{p}$ and $z_{p}$ are the radial and axial coordinates of the point of origin, respectively. Note that in theory, cosine can be used instead of tangent. However, the mathematical definition for cosine is such that positive small angle and negative small angle both yield positive cosine values. Thus, inverting cosine to obtain $\theta$ in the present coordinate system can sometimes yield angle values that are in the wrong quadrant. Tangent does not have this issue.

Equation (8) is the integral equation for calculating the divergence angle of each jet. Note that this is a measure of the spread in the plume around the travel angle, which is allowed to be non-zero in the current formulation.

$$
\cos \delta_{\mathrm{pj}}=\frac{2 \pi \int_{0}^{\infty} \mathrm{j}_{\mathrm{z}}(\mathrm{r}) \cos \left(\theta-\theta_{\mathrm{pj}}\right) \mathrm{rdr}}{2 \pi \int_{0}^{\infty} \mathrm{j}_{\mathrm{Z}}(\mathrm{r}) \mathrm{rdr}}, \cos \left(\theta-\theta_{\mathrm{pj}}\right)=\cos \left(\tan ^{-1}\left(\frac{\mathrm{r}-\mathrm{r}_{\mathrm{p}}}{\mathrm{z}-\mathrm{z}_{\mathrm{p}}}\right)-\theta_{\mathrm{pj}}\right)
$$

Replacing the limits of integration with the appropriate values on the $-\mathrm{R}$ sign and replacing $\theta_{\mathrm{pj}}$ with $\theta_{\mathrm{nj}}$ will give the equation for the $-\mathrm{R}$ jet.

In step two, the variations in the travel and divergence angles with axial distance is used to compute the error metrics. To simplify the calculations, the travel angle is assumed to be small. This assumption implies that the radial coordinate of the origin has a much greater influence on the travel angle than the axial coordinate, and that the axial coordinate has a much greater influence on the divergence angle than the radial coordinate. Pairing up the two controls with the two variables greatly simplifies the feedback equations. Equations (9) and (10) show the feedback equations for determining the next guess on the point of origin.

$$
\begin{aligned}
& r_{\mathrm{p}, \mathrm{k}+1}=\mathrm{r}_{\mathrm{p}, \mathrm{k}}-\beta_{1} \operatorname{sign}\left(\frac{\mathrm{r}_{\mathrm{p}, \mathrm{k}-1}-\mathrm{r}_{\mathrm{p}, \mathrm{k}}}{\mathrm{E}_{\theta, \mathrm{pj}, \mathrm{k}-1}-\mathrm{E}_{\theta, \mathrm{pj}, \mathrm{k}}}\right) \mathrm{E}_{\theta, \mathrm{pj}, \mathrm{k}} \\
& \mathrm{z}_{\mathrm{p}, \mathrm{k}+1}=\mathrm{z}_{\mathrm{p}, \mathrm{k}}-\beta_{2} \operatorname{sign}\left(\frac{\mathrm{z}_{\mathrm{p}, \mathrm{k}-1}-\mathrm{z}_{\mathrm{p}, \mathrm{k}}}{\mathrm{E}_{\delta, \mathrm{pj}, \mathrm{k}-1}-\mathrm{E}_{\delta, \mathrm{pj}, \mathrm{k}}}\right) \mathrm{E}_{\delta, \mathrm{pj}, \mathrm{k}}
\end{aligned}
$$

Where the subscript $\mathrm{k}$ indicates the $\mathrm{k}$-th iteration, $\beta_{1}$ and $\beta_{2}$ are tuning parameters to control the speed of convergence, $\mathrm{E}_{\theta, \mathrm{p}, \mathrm{k}}$ is the error metric on the travel angle, and $\mathrm{E}_{\delta, \mathrm{pj}, \mathrm{k}}$ is the error metric on the divergence angle. The function "sign" is equal to -1 or +1 depending on the sign of the content. If the sign functions are replaced with the contents of the sign functions, the above two equations would be the same as Newton's method for root solving. However, the overdetermined nature of the problem seemed to give rise to convergence issue for Newton's method. Instead, the sign function was used to maintain the ability of Newton's method to determine the right direction to guess while the tuning parameters were used to control convergence speed. Note that the tuning parameters also control the accuracy of the guess. Due to the presence of noise in the data, the feedback algorithm tends to dance back and forth around the true point of origin. The amplitude of this numerical oscillation and the convergence speed of the algorithm both increase with $\beta$. Too high of a value of $\beta$ can cause the algorithm to oscillate wildly and not converge. As such, $\beta_{1}$ and $\beta_{2}$ were individually tuned to achieve adequately small numerical oscillation amplitudes while maintaining a decent convergence speed. Note that this simplified feedback algorithm will still converge even if the travel angle is not small but will take longer to converge than a more general feedback algorithm that links each error metric to both coordinates. On the hand, this simplified algorithm is numerically more stable than a more general algorithm. 
Equations (11) and (12) show the error metrics used for this study.

$$
\begin{aligned}
& \mathrm{E}_{\theta, \mathrm{pj}}=\left[\frac{1}{\mathrm{~N}} \sum\left(\theta_{\mathrm{pj}}-\bar{\theta}_{\mathrm{pj}}\right)^{4}\right]^{1 / 4} \\
& \mathrm{E}_{\delta, \mathrm{pj}}=\left[\frac{1}{\mathrm{~N}} \sum\left(\delta_{\mathrm{pj}}-\bar{\delta}_{\mathrm{pj}}\right)^{4}\right]^{1 / 4}
\end{aligned}
$$

Where $\bar{\theta}_{\mathrm{pj}}$ is the mean travel angle, $\bar{\delta}_{\mathrm{pj}}$ is the mean divergence angle, and $\mathrm{N}$ is the number of axial positions over which the angles were calculated. Only data from the jet analysis zone $(0.2<Z<0.5)$ were used in the calculations. If the $4^{\text {th }}$ power is replaced with the $2^{\text {nd }}$ power and the quartic root replaced with the square root, Eqs. (11) and (12) become root-mean-square of the difference between the angles and the mean angles. The $4^{\text {th }}$ power was used to increase the sensitivity of the error to difference between the guess location and the true point of origin. The addition of noise to the data set creates many local minima in the vicinity of the global minimum that can destabilize the convergence process. Trials were performed with both the $2^{\text {nd }}$ and the $4^{\text {th }}$ power error metrics and the feedback algorithm was much more stable with the $4^{\text {th }}$ power error metrics.

Figure 7 shows an example of the convergence plot for the iterative pathfinding method. The data set is from the $300 \mathrm{M}$ operating at $500 \mathrm{~V}, 20 \mathrm{~kW}$. The black lines show the successive guesses in the coordinates of the $+\mathrm{R}$ jet while the red lines (grey if printed in black and white) show the guesses for the $-\mathrm{R}$ jet. For the $-\mathrm{R}$ jet, the negative of the radial coordinate is plotted so that the difference between the absolute value of the radial coordinates of the two jets is easier to see. Note that currently the program will run 500 trials regardless of whether convergence is detected. The main purpose of the program was to test out the concepts behind iterative pathfinding. The convergence algorithm can likely be further refined. Figure 8 shows the total beam current, travel angle, and divergence angle at the end of the analysis. The limit of integration used for this example was the threshold-based limits with a fraction of 0.002 (i.e. $0.2 \%$
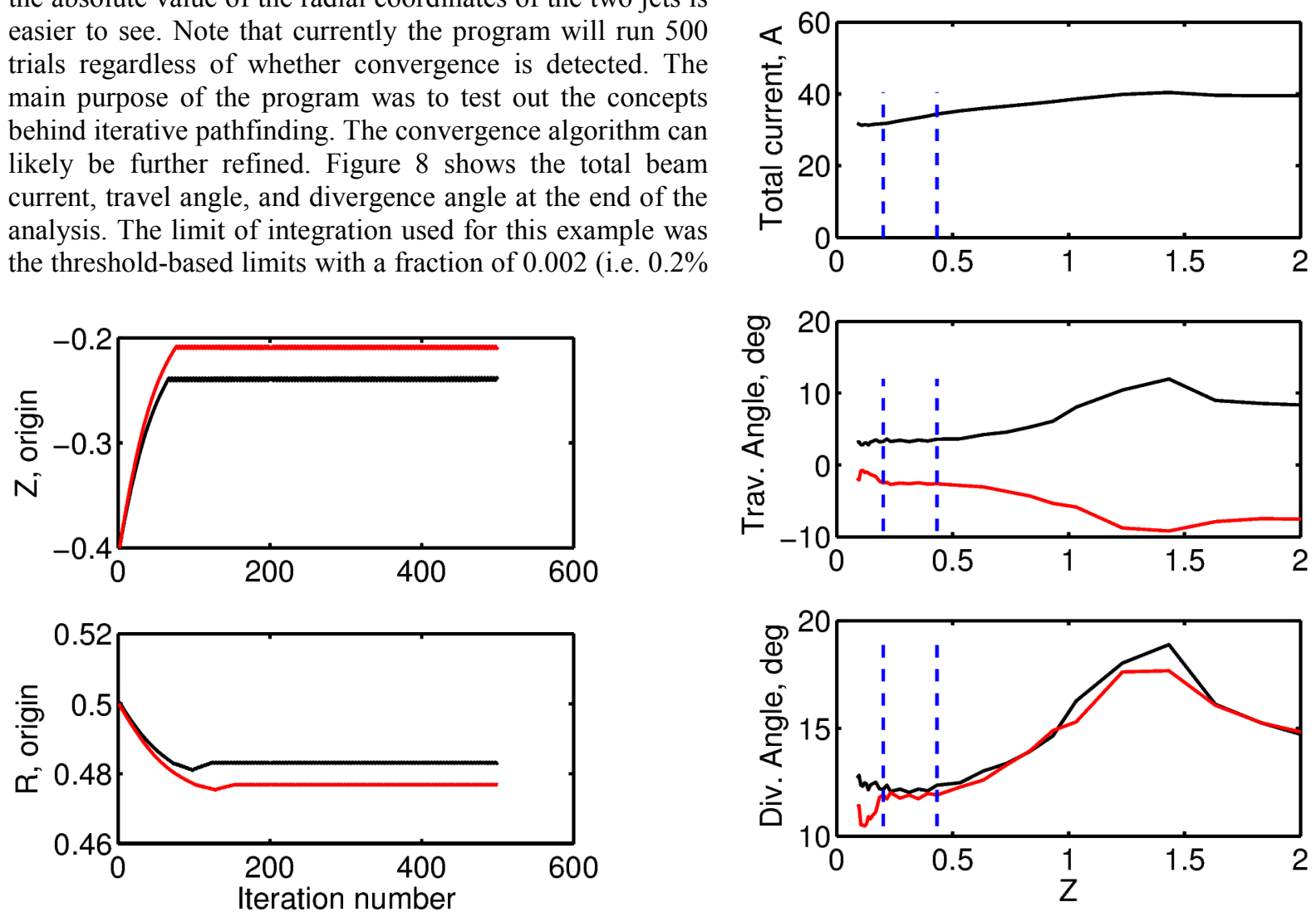

Figure 7. Example convergence plot for the iterative pathfinding method. $(300 \mathrm{M}$ operating at $500 \mathrm{~V}, 20 \mathrm{~kW})$

The black lines represent the origin for the $+R$ jet and the red lines represent the origin for the $-R$ jet. Note that the negative of the $R$ value for the $-R$ jet is plotted instead of the actual value for convenience.

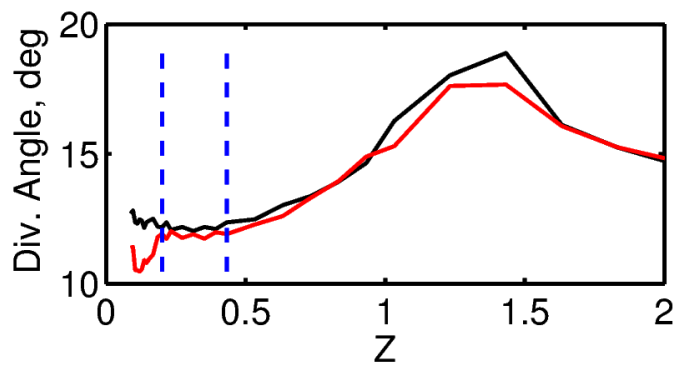

Figure 8. Example plot of total beam current, travel angle, and divergence angle versus axial position. (300M operating at $500 \mathrm{~V}, 20 \mathrm{~kW})$

In all subplots, vertical lines indicate the boundaries of the jet analysis zone. For the angle plots, the black lines represent the origin for the $+R$ jet and the red lines represent the origin for the $-R$ jet.

American Institute of Aeronautics and Astronautics 
of peak current density). From Fig. 8, one can see that the values of the various parameters can be quite different just upstream of $Z=0.2$ than in the jet analysis zone. This trend appeared at many conditions for both the $300 \mathrm{M}$ and the 457Mv2. One possible explanation is that the jets are still accelerating upstream of $Z=0.2$ since part of the acceleration zone is known to reside beyond the exit plane for these thrusters. ${ }^{12}$ Then again, it is unclear how this acceleration could affect the Faraday probe results the way it does.

To calculate the overall divergence angle as seen from far away, the momentum of each jet is assumed to be decompose-able into the momenta of two collimated beams. The beams each carry half of the momentum of the associated jet and radiates out at plus/minus the divergence angle with respect to the travel angle of the jet. This approach is represented mathematically in the Eq. (13).

$$
\delta=\frac{\left|\theta_{\mathrm{pj}}+\delta_{\mathrm{pj}}\right|+\left|\theta_{\mathrm{pj}}-\delta_{\mathrm{pj}}\right|+\left|\theta_{\mathrm{nj}}+\delta_{\mathrm{nj}}\right|+\left|\theta_{\mathrm{nj}}-\delta_{\mathrm{nj}}\right|}{4}
$$

\section{Limits of Integration}

As previously mentioned, choice of the limits of integration is a big issue when analyzing near-field Faraday probe data. Threshold-based limits were selected for this study because of its scalability. To re-iterate, limits for threshold-based limits are selected by find the radial locations where the current density has dropped below a certain fraction (called the threshold fraction) of the peak current density in the plasma beam. Several values of the threshold fraction were tried for this study. Part of the results will be shown in a sensitivity study within the Results section. The fraction values were picked to be as low as possible without generating unphysical results. However, while experimenting with the fraction values, the authors noticed there were values below which the feedback algorithm will not converge. One possible explanation is that the noise in the data, which can be a big fraction of the mean current density at large values of $\mathrm{R}$, can overwhelm the feedback algorithm. If the integration limits are not sufficiently small, the noise recorded at large radial positions, amplified by the associated element area in the integration equation, can adversely affect the stability of the convergence process. Further investigation is required on this phenomenon.

Curiously, the minimum fraction of peak current density needed to achieve convergence for the $300 \mathrm{M}$ data set is slightly lower than for the $457 \mathrm{Mv} 2$ data set; Perhaps suggesting that the $457 \mathrm{Mv} 2$ data set is relatively noisier. The minimum value of the fraction needed to achieve convergence for the $300 \mathrm{M}$ is $\sim 002$ (i.e. $0.2 \%$ of the peak current density), while that for the $457 \mathrm{Mv} 2$ is $\sim 0.005$. To make direct comparison between the two thrusters possible, results will be shown for limits based on both $0.2 \%$ and $0.5 \%$ of peak current density. Figure 9 shows an example of the flooded current density contour after the cathode plume has been subtracted out. The red dashed lines indicate the limits of integration as functions of axial position. Data set comes from the $300 \mathrm{M}$ operating at $500 \mathrm{~V}, 20 \mathrm{~kW}$. Integration limits are set to $0.2 \%$ of the peak current density.

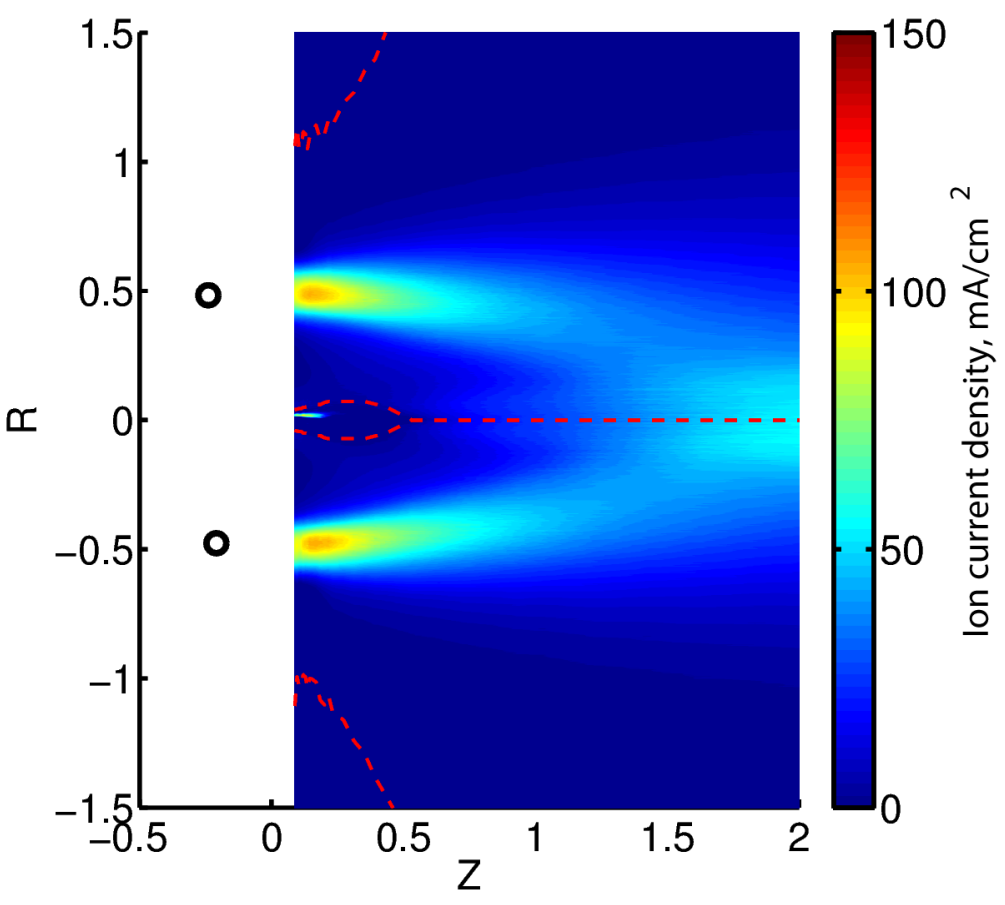

Figure 9. Flooded current density contour with dashed lines showing the limits of integration. (300M operating at $500 \mathrm{~V}, 20$ kW)

Integration limits set to $0.2 \%$ of peak current density. 


\section{Results}

\section{A. Experimental Data Sets}

To validate the iterative pathfinding method for analyzing near-field Faraday probe data, data was taken from a prior study on the NASA-300M and NASA-457Mv2 Hall thruster. ${ }^{11}$ The thrusters are briefly described below. Detailed description of the thruster and experimental setup can be found in the prior study. ${ }^{11}$

The NASA-300M and the NASA-457Mv2 are magnetic-layer Hall thrusters designed based on the principles outlined in Manzella's dissertation work. ${ }^{18}$ Both thrusters were originally developed for high-specific-impulse missions ${ }^{19}$. The two thrusters have lens-type magnetic field topology. ${ }^{20,21}$ Each thruster ran with a centrally-mounted hollow cathode derived from the discharge cathode for NASA's Evolutionary Xenon Thruster (NEXT). ${ }^{19}$ For the data used in this paper, the magnetic field settings of the thrusters were optimized to give roughly symmetric shapes while maximizing anode efficiency. The cathode flow fraction was maintained at $8 \%$.

The nominal operating condition of the $300 \mathrm{M}$ is $500 \mathrm{~V}, 20 \mathrm{~kW}$. The data sets that will be shown for the $300 \mathrm{M}$ span seven operating conditions with discharge voltages between 200 to $500 \mathrm{~V}$, discharge currents between 20 to 67 $\mathrm{A}$, and discharge powers between 10 and $20 \mathrm{~kW}$. The anode efficiency of this thruster varies from 57 to $73 \%$ over the tested operating conditions. The nominal operating condition of $457 \mathrm{Mv} 2$ is $500 \mathrm{~V}, 100 \mathrm{~A}$. The data sets that will be shown for the $457 \mathrm{Mv} 2$ span 13 operating conditions with discharge voltages between 200 to $500 \mathrm{~V}$, discharge currents between 40 to $100 \mathrm{~A}$, and discharge powers between 10 to $50 \mathrm{~kW}$. The anode efficiency of the $457 \mathrm{Mv} 2$ varies from 55 to $70 \%$ over the tested operating conditions.

Additional data from a far-field Faraday probe study of the $300 \mathrm{M}$ is also included in order to compare the differences between the two types of Faraday probe studies. ${ }^{22}$ The operating conditions of the $300 \mathrm{M}$ studied during the far-field Faraday probe test matches those studied during the near-field Faraday probe test. The data from the two types of Faraday probe were taken using experimental setups that were identical in every way except for the diagnostics in use.

\section{B. Current Density Contour Before and After Cathode Plume Removal}

This section shows flooded current density contour plots before and after the cathode plume had been removed. Generally, the cathode plume removal results can be placed under one of three categories depending on how much plume remains along the thruster centerline in the near-field region after removal; they are "clean", "plume", and "anomalous". The "clean" category refers to conditions for which no noticeable plasma remains (except the occasional spurious spike) in the region downstream of the cathode, prior to plume merging. The "plume" category refers to what appears to be a plasma plume somewhat downstream of the cathode that remains after the cathode plume removal process is applied. This is different from a spurious spike because the plume is wider and denser than what one would expect from curve-fit misalignment. The program is able to exclude this plume from the analysis domain the same way it excludes spurious spikes. The "anomalous" category is similar to the "plume" category except the plasma plume that remains downstream of the cathode after the cathode plume removal process is denser, and the program is not able to exclude the "anomalous" plasma from the beam analysis. One possible reason why the program could fail to exclude this anomalous plasma is that the data may be too noisy in that region. For the figures in this section, the "before" plots are overlaid with red dashed lines showing the cathode curve-fit zone while the "after" plots are overlaid with red dashed lines showing the integration limits corresponding to $0.2 \%$ of peak current density.

Figures 10 to 12 show the flooded current density contour plots before and after the cathode plume removal process. Figure 10 corresponds to the $300 \mathrm{M}$ operating at $500 \mathrm{~V}, 20 \mathrm{~kW}$, and falls in the "clean" category. Figure 11 corresponds to the $457 \mathrm{Mv} 2$ operating at $250 \mathrm{~V}, 20 \mathrm{~kW}$, and falls in the "plume" category. Figure 12 corresponds to the $300 \mathrm{M}$ operating at $300 \mathrm{~V}, 20 \mathrm{~kW}$, and falls in the "anomalous" category.

For the $300 \mathrm{M}$, data sets for 6 of the 7 tested conditions fall in the "clean" category; 1 data set falls in the "anomalous" category. For the 457Mv2, data sets for 6 of the 13 tested conditions can be considered "clean", 6 more falls under the "plume" category, and 1 falls in the "anomalous" category. Since the program is able to exclude the plume in the "plume" category data sets, there does not appear to be any issues with applying the beam analysis on 18 of the 20 tested thruster/conditions. For the two data sets that fall in the "anomalous" category, the uncertainty in the analysis results is likely to be higher, though the actual total current represented by the anomalous plume is no more than a few percent of the beam current due to the associated integration element area being small. It is currently unclear how best to estimate the uncertainties in the results of the iterative pathfinding method. Instead of calculating the increase in uncertainties, the data sets that fall under the "anomalous" category will simply be noted in the results. 

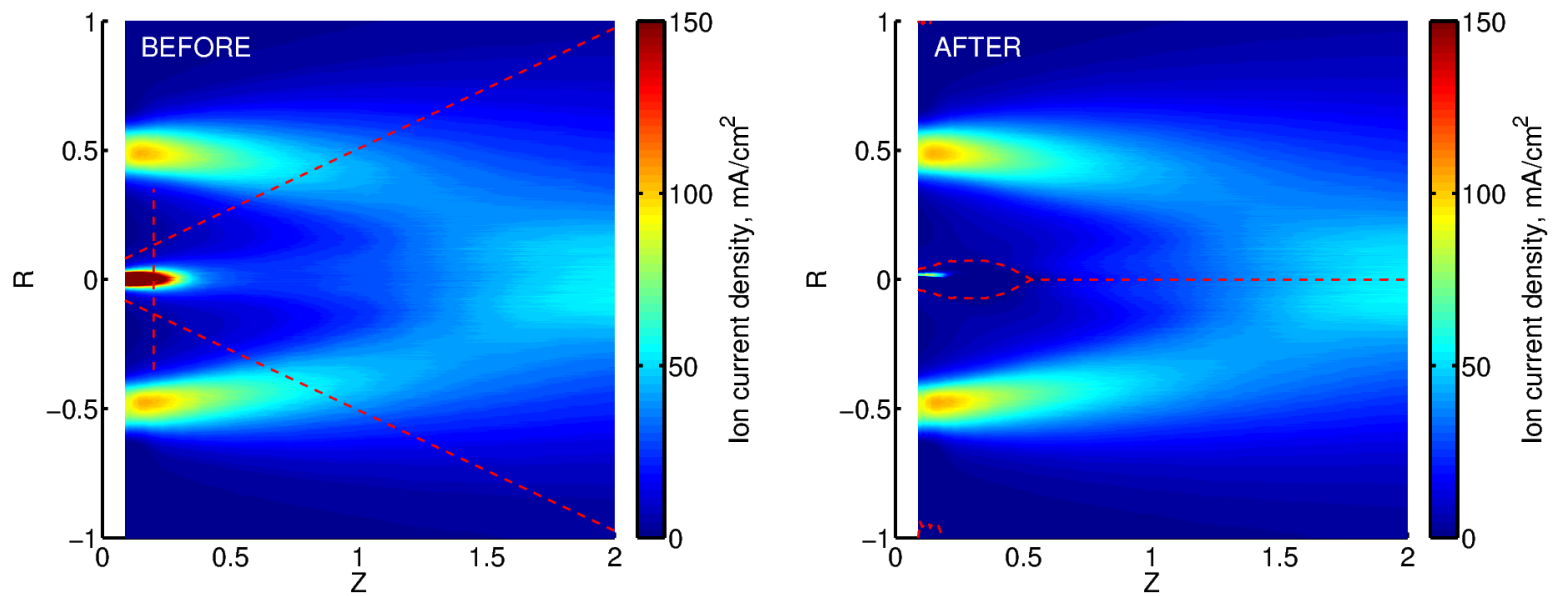

Figure 10. Flooded contours of current density before and after cathode plume removal for the 300M operating at $500 \mathrm{~V}, 20 \mathrm{~kW}$.
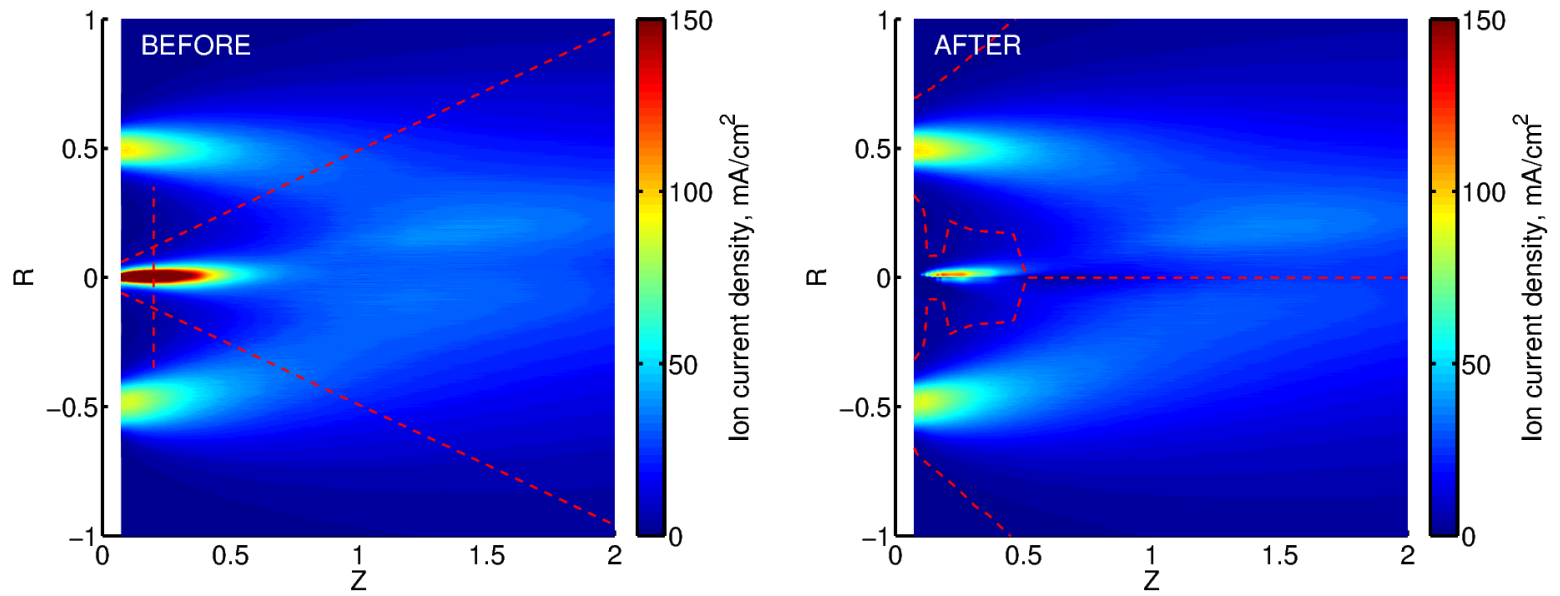

Figure 11. Flooded contours of current density before and after cathode plume removal for the $457 \mathrm{Mv} 2$ operating at $250 \mathrm{~V}, 20 \mathrm{~kW}$.
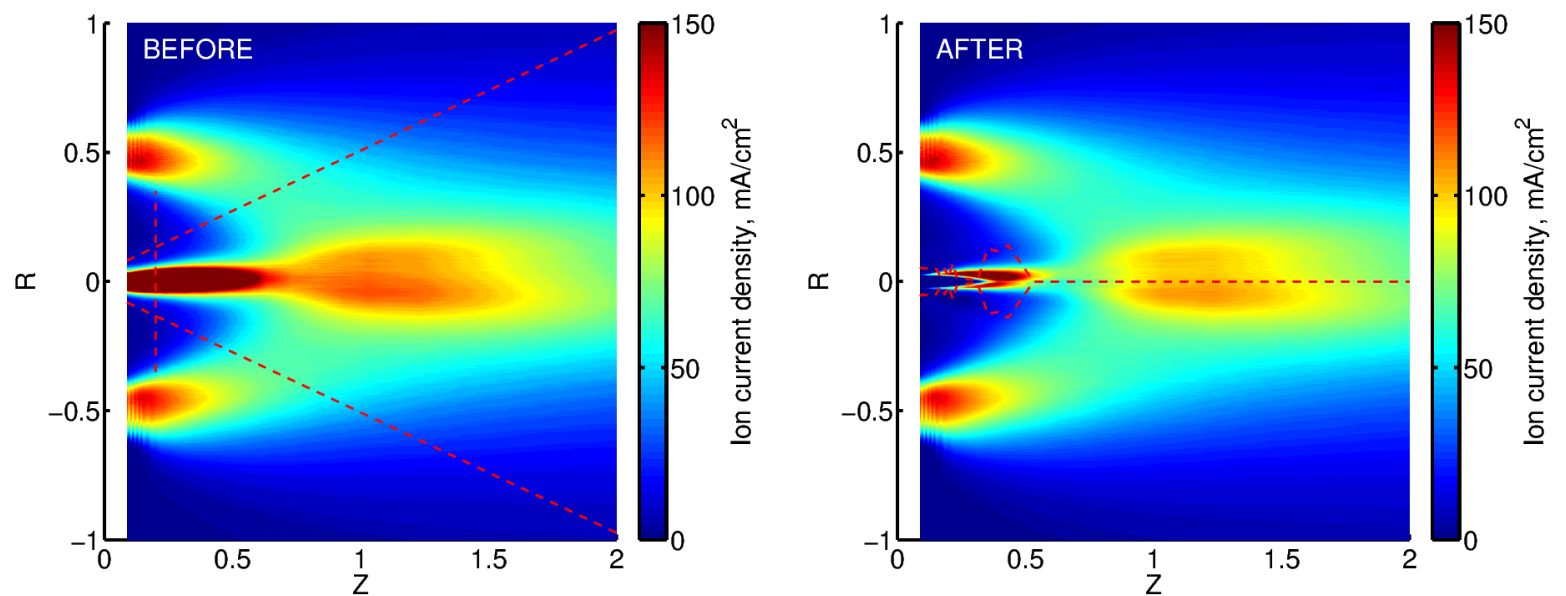

Figure 12. Flooded contours of current density before and after cathode plume removal for the $300 \mathrm{M}$ operating at $300 \mathrm{~V}, 20 \mathrm{~kW}$. 
The presence of a plasma plume downstream of the cathode even after applying the cathode plume removal process implies that the probe collects more plasma there than can be accounted for by a free-expanding jet. However, what is really interesting about the observed results is that it varies greatly across operating conditions. For example, of the 7 cases from the $300 \mathrm{M}$, only 1 had a noticeable central plume after cathode removal. Yet, for the $457 \mathrm{Mv} 2$, many cases displayed this unusual characteristic. Of the 13 cases from the $457 \mathrm{Mv} 2$, all 5 cases that operated at 100 A discharge current displayed a sizable downstream cathode plume, while both cases that involved 80 A operation displayed a small downstream cathode plume. The remaining 6 cases involved operating at less than 80 A discharge current and displayed no noticeable downstream cathode plume after applying cathode plume removal. It would appear that the left-over plasma plume downstream of the cathode is linked to the discharge current (possible the current density) that the thruster is operating at.

One possible explanation for the presence of left-over plasma plume downstream of the cathode is that the cathode removal process does not operate correctly for a large cathode current. For instance, if there is significant plasma generation downstream of the cathode, particularly beyond $Z=0.2$, the extra plasma would not be picked up by the cathode plume removal algorithm. The amount of near-field plasma potential data in the cathode region on the $300 \mathrm{M}$ and $457 \mathrm{Mv} 2$ is somewhat limited. ${ }^{10,12}$ Based on this limited data, the area downstream of the cathode is observed to contain a long strip of negatively biased region. This region is radially thin $(-0.1<\mathrm{R}<0.1)$ and stretches out to about $Z=1$. However, this region is only about 5 to $10 \mathrm{~V}$ lower than the surrounding plasma and the potential drop is arguably not high enough to ionize a meaningful amount of plasma.

Another possible explanation is that the left-over plume is part of the "central spike" phenomenon that has been observed in many Hall thrusters. ${ }^{7,8}$ While the exact nature of the central spike is unknown, the presence of plasma in the region just downstream of the thruster along the thruster centerline has been confirmed even when the cathode is not centrally mounted. ${ }^{7}$

A third possible explanation is that the merging of beam plasma occurs much further upstream when the cathode flow is high. Recall that the cathode flow fraction was fixed at $8 \%$. Since conditions with high discharge current corresponded to high anode mass flow rates, they also corresponded to high cathode mass flow rates. The increased mass flow may have enhanced the mobility of the plasma in the vicinity, allowing the plume to merge sooner after exiting the thruster than otherwise possible. 


\section{Total Ion Current and Divergence Angle}

In order to obtain an accurate estimate of the total ion current, the effect of secondary electron emission (SEE) must be addressed. Secondary electrons born on a negatively biased probe will accelerate away from the probe. This effect adds extra current to the probe measurement that is indistinguishable from the collected ion current. Faraday probes are typically constructed from materials with low SEE yield like molybdenum and tungsten. ${ }^{16,25,26}$ The probe in cited data set uses molybdenum. ${ }^{11}$ In the past, researchers assumed the effect

Table 1. Summary of SEE data for xenon ion bombardment of molybdenum. ${ }^{23,24}$

\begin{tabular}{cc}
\hline $\begin{array}{c}\text { Bombarding } \\
\text { particle }\end{array}$ & $\begin{array}{c}\text { SEE yield of } \\
\text { molybdenum }\end{array}$ \\
\hline $\mathrm{Xe}^{+}$ & 0.022 \\
$\mathrm{Xe}^{2+}$ & 0.20 \\
$\mathrm{Xe}^{3+}$ & 0.70 \\
\hline
\end{tabular}
of SEE can be ignored if such materials were used. While the singly-charged xenon-induced SEE yield for molybdenum and tungsten are indeed negligible (0.013 to 0.022), the doubly-charged xenon-induced SEE yield are roughly 10 times higher than the singly-charged yield, and the triply-charged SEE yield are roughly 35 times higher than the singly-charged yield. ${ }^{23,} 24,27$ Table 1 summarizes the SEE yield values for multiply-charged xenon bombarding molybdenum. The singly-charged and doubly-charged xenon-induced yields are averages of the SEE yield data for ion energies in the range of 200 to $800 \mathrm{eV}$ in Hagstrum's 1956 work. $^{23}$ The triply-charged xenoninduced yield of molybdenum could not be found in the literature. The value in Table 1 is a projected value based on the similarity in yield between tungsten and molybdenum. The ratio of triply-charged induced yield to doublycharged induced yield for tungsten is 3.5 , so the yield for molybdenum is approximated to be $3.5 * 0.2$, or $0.7 .^{24}$

In a past work, Huang, et al., devised an approximate formula to estimate the effect of SEE based on current fractions of multiply-charged species. ${ }^{22}$ This formula is reproduced in Eq. (14).

$$
\mathrm{J}=\frac{\mathrm{J}_{\mathrm{FP}}}{1+\gamma_{\mathrm{eff}}}=\mathrm{J}_{\mathrm{FP}} * \sum_{\mathrm{k}} \frac{\Omega_{\mathrm{k}}}{1+\gamma_{\mathrm{k}}}
$$

Where $\mathrm{J}$ is the actual ion current density, $\mathrm{J}_{\mathrm{FP}}$ is the current density measured by a Faraday probe, $\gamma_{\mathrm{eff}}$ is the effective SEE yield, $\gamma_{\mathrm{k}}$ is the SEE yield associated with bombardment by the k-th species, and $\Omega_{\mathrm{k}}$ is the current fraction of the k-th species. Using Eq. (14), we can write a new equation to show the definition of the effective SEE yield for the Faraday probe, shown in Eq. (15).

$$
\gamma_{\mathrm{eff}}=\frac{1}{\left(\sum_{\mathrm{k}} \frac{\Omega_{\mathrm{k}}}{1+\gamma_{\mathrm{k}}}\right)}-1
$$

Using the Eq. (14) requires knowledge of the current fraction, which is typically obtained using a Wien filter (a.k.a. ExB probe). However, current fraction measurements were only obtained for the $300 \mathrm{M}$, and not the $457 \mathrm{Mv} 2$. Since the main purpose of this study is to determine the effectiveness of the iterative pathfinding method, an approximation will be used for the effective SEE yield. From past measurements, the average effective SEE yield for the $300 \mathrm{M}$ over the range of operating conditions treated in this study was found to be $0.077 \pm 0.012 .{ }^{22}$ The $457 \mathrm{Mv} 2$ was designed based on the same principle as the $300 \mathrm{M}$, operates at very similar current density, and the data set being treated span very similar discharge voltages. Thus, by assuming the effective SEE yield is 0.077 for all data treated in this study, the random error in the total current rises by $\sim 1 \%$ while a $7.7 \%$ systematic error is removed. 
Table 2 lists the operating conditions and the angle results from applying the iterative pathfinding method with $0.2 \%$ and $0.5 \%$ threshold-based limits. An asterisk is added in front of the discharge voltage for each of the two operating conditions with "anomalous" plume that remains after cathode plume removal. A dash is shown if applying the new method with the corresponding threshold-based limits does not result in convergence within 500 iterations or converge to an improbable location. For example, when the feedback algorithm is barely stable, it will sometimes converge to a positive value of $Z$, which base on known Hall thruster physics is highly improbable. The data set for the $457 \mathrm{Mv} 2$ operating at $500 \mathrm{~V}, 50 \mathrm{~kW}$ is a unique case in that the threshold fraction for integration limits must be $1.5+\%$ in order to achieve convergence. It is unclear why this one case requires such a high threshold fraction in order for the feedback algorithm to work stably.

Studying Table 2 yields some insights into the new method. Using smaller threshold fraction for the integration limits correspond to larger angle values. This is expected because smaller threshold fraction means current density at larger radial position will be used in the angle calculations. The travel angle is on the average within a few degrees (except for one case) and is positive on the $+\mathrm{R}$ side, negative on the $-\mathrm{R}$ side. This trend implies that there is a small outward bias in the travel angles of the plasma jets. One possible explanation for the small outward bias is the swirl in the ions applied by the magnetic field. Alternately, the outward bias in the travel angle could be a systematic error in the new analysis method. Either way, the travel angle is small enough that associated cosine thrust loses are negligible. The case of $457 \mathrm{Mv} 2$ operating at $200 \mathrm{~V}, 20 \mathrm{~kW}$ shows a noticeably higher travel angle than the other cases. Trying several different threshold fraction values showed that the program is indeed converging properly. It is unclear at this point whether the large travel angles are real.

Table 2. Summary of travel and divergence angles for two different threshold-based limits.

\begin{tabular}{|c|c|c|c|c|c|c|c|c|c|c|c|c|c|}
\hline \multirow[b]{2}{*}{ 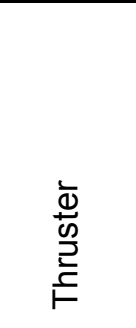 } & \multirow{2}{*}{ 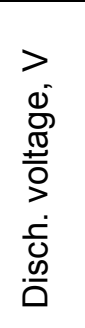 } & \multirow{2}{*}{ 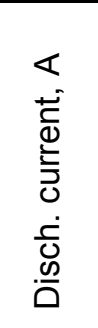 } & \multirow{2}{*}{ 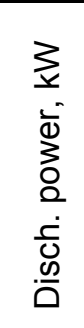 } & \multicolumn{2}{|c|}{$\begin{array}{c}\text { Overall } \\
\text { divergence } \\
\text { angle, deg. }\end{array}$} & \multicolumn{2}{|c|}{$\begin{array}{c}\text { Travel } \\
\text { angle, deg. } \\
(+\mathrm{R} \text { side })\end{array}$} & \multicolumn{2}{|c|}{$\begin{array}{c}\text { Divergence } \\
\text { angle, deg. } \\
(+\mathrm{R} \text { side })\end{array}$} & \multicolumn{2}{|c|}{$\begin{array}{c}\text { Travel } \\
\text { angle, deg. } \\
(-\mathrm{R} \text { side })\end{array}$} & \multicolumn{2}{|c|}{$\begin{array}{l}\text { Divergence } \\
\text { angle, deg. } \\
\text { (-R side) }\end{array}$} \\
\hline & & & & $\begin{array}{c}0.2 \\
\%\end{array}$ & $\begin{array}{c}0.5 \\
\%\end{array}$ & $\begin{array}{c}0.2 \\
\%\end{array}$ & $\begin{array}{c}0.5 \\
\%\end{array}$ & $\begin{array}{c}0.2 \\
\%\end{array}$ & $\begin{array}{c}0.5 \\
\%\end{array}$ & $\begin{array}{c}0.2 \\
\%\end{array}$ & $\begin{array}{c}0.5 \\
\%\end{array}$ & $\begin{array}{c}0.2 \\
\%\end{array}$ & $\begin{array}{c}0.5 \\
\%\end{array}$ \\
\hline \multirow{7}{*}{$300 \mathrm{M}$} & 200 & 50.3 & 10.1 & 21.6 & 19.5 & 8.0 & 4.5 & 22.0 & 19.8 & -6.6 & -3.4 & 21.2 & 19.2 \\
\hline & 300 & 33.3 & 10.0 & 11.6 & 8.6 & 4.5 & 2.7 & 11.1 & 8.5 & -3.5 & -1.2 & 12.1 & 8.7 \\
\hline & *301 & 67.3 & 20.3 & 16.5 & 15.2 & 5.5 & 3.8 & 16.4 & 15.2 & -4.3 & -2.8 & 16.6 & 15.2 \\
\hline & 401 & 24.9 & 10.0 & 12.9 & 9.4 & 4.7 & 2.3 & 12.3 & 9.1 & -4.2 & -1.2 & 13.5 & 9.6 \\
\hline & 399 & 50.0 & 20.0 & 10.1 & 8.5 & 1.9 & 1.0 & 10.0 & 8.5 & -0.9 & 0.2 & 10.2 & 8.5 \\
\hline & 501 & 19.9 & 10.0 & 14.4 & 10.4 & 5.4 & 2.4 & 13.7 & 10.1 & -5.2 & -1.3 & 15.0 & 10.6 \\
\hline & 501 & 40.6 & 20.3 & 12.0 & 10.4 & 3.4 & 2.3 & 12.2 & 10.7 & -2.6 & -1.4 & 11.8 & 10.1 \\
\hline \multirow{13}{*}{ 457Mv2 } & 202 & 49.1 & 9.9 & - & 13.6 & - & 5.3 & - & 13.4 & - & -3.1 & - & 13.7 \\
\hline & *200 & 99.8 & 20.0 & - & 24.7 & - & 27.2 & - & 16.0 & - & -22.3 & - & 14.8 \\
\hline & 250 & 80.2 & 20.1 & - & 15.7 & - & 4.9 & - & 15.2 & - & -4.3 & - & 16.1 \\
\hline & 250 & 99.8 & 25.0 & - & 17.6 & - & 6.4 & - & 17.3 & - & -6.4 & - & 17.9 \\
\hline & 301 & 66.4 & 20.0 & - & 12.5 & - & 1.9 & - & 13.6 & - & 0.2 & - & 11.4 \\
\hline & 300 & 99.8 & 29.9 & - & 16.1 & - & 5.5 & - & 17.4 & - & -1.9 & - & 14.8 \\
\hline & 400 & 49.7 & 19.9 & - & 11.4 & - & 5.7 & - & 12.0 & - & -2.3 & - & 10.8 \\
\hline & 400 & 74.8 & 29.9 & - & 12.5 & - & -0.4 & - & 13.3 & - & 1.5 & - & 11.7 \\
\hline & 401 & 98.2 & 39.4 & - & 10.9 & - & 3.3 & - & 10.1 & - & -3.1 & - & 11.8 \\
\hline & 501 & 40.5 & 20.3 & - & 12.7 & - & 6.4 & - & 13.4 & - & -2.4 & - & 12.0 \\
\hline & 500 & 60.1 & 30.1 & - & 10.6 & - & 4.1 & - & 10.6 & - & -1.9 & - & 10.6 \\
\hline & 501 & 79.7 & 39.9 & - & 11.7 & - & 3.4 & - & 11.6 & - & -1.6 & - & 11.9 \\
\hline & 501 & 101.1 & 50.7 & - & - & - & - & - & - & - & - & - & - \\
\hline
\end{tabular}

American Institute of Aeronautics and Astronautics 
Table 3 lists the total beam current, current utilization efficiency, overall divergence angle, and divergence efficiency by operating conditions. The current utilization efficiency and the divergence efficiency are defined in Eqs. (16) and (17), respectively. The current utilization efficiency describes loss in efficiency associated with part of the discharge current being carried by electrons instead of ions. The divergence efficiency describes loss in efficiency associated with plume divergence. Both are typically calculated from Faraday probe data.

$$
\begin{gathered}
\eta_{b}=\frac{I_{b}}{I_{d}} \\
\eta_{d}=(\cos \delta)^{2}
\end{gathered}
$$

Where $I_{b}$ is the total beam current and $I_{d}$ is the discharge current. From Table 3 we see that using smaller threshold fraction for the integration limits correspond to larger total beam current, likely due to an expansion of the integration domain. For the lack of a better method to determine the right threshold fraction value, this study will rely on far-field Faraday probe results to calibrate the near-field Faraday probe results. For state-of-the-art Hall thrusters, this percentage is typically $70-80 \%,{ }^{8,28-30}$ so a fraction value of $0.2 \%$ is a closer fit than $0.5 \%$. However, cases for the $457 \mathrm{Mv} 2$ generally did not converge when a fraction value of $0.2 \%$ was used. Further investigation with a refined convergence algorithm and more comparisons between near-field and far-field Faraday probe data is needed to determine whether $0.2 \%$ is the correct threshold value to use.

\begin{tabular}{|c|c|c|c|c|c|c|c|c|c|c|c|}
\hline \multirow[b]{2}{*}{ 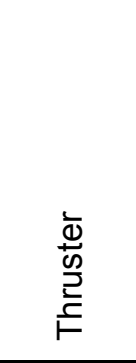 } & \multirow{2}{*}{$\begin{array}{l}> \\
0 \\
0 \\
\mathbb{0} \\
\frac{\pi}{0} \\
> \\
\frac{5}{0} \\
. \frac{\infty}{0}\end{array}$} & \multirow{2}{*}{ 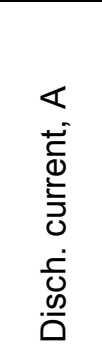 } & \multirow{2}{*}{ 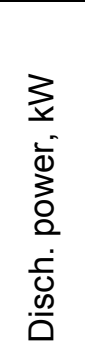 } & \multicolumn{2}{|c|}{$\begin{array}{c}\text { Total beam } \\
\text { current, A } \\
\text { (Corrected } \\
\text { for SEE) } \\
\end{array}$} & \multicolumn{2}{|c|}{$\eta_{b}$} & \multicolumn{2}{|c|}{$\begin{array}{c}\text { Overall } \\
\text { divergence } \\
\text { angle, deg. }\end{array}$} & \multicolumn{2}{|c|}{$\eta_{d}$} \\
\hline & & & & $\begin{array}{c}0.2 \\
\%\end{array}$ & $\begin{array}{c}0.5 \\
\% \\
\end{array}$ & $\begin{array}{c}0.2 \\
\% \\
\end{array}$ & $\begin{array}{c}0.5 \\
\% \\
\end{array}$ & $\begin{array}{c}0.2 \\
\% \\
\end{array}$ & $\begin{array}{c}0.5 \\
\% \\
\end{array}$ & $\begin{array}{c}0.2 \\
\% \\
\end{array}$ & $\begin{array}{c}0.5 \\
\% \\
\end{array}$ \\
\hline \multirow{7}{*}{$300 M$} & 200 & 50.3 & 10.1 & 40.5 & 31.7 & 0.750 & 0.630 & 21.6 & 19.5 & 0.864 & 0.889 \\
\hline & 300 & 33.3 & 10.0 & 26.4 & 22.1 & 0.737 & 0.664 & 11.6 & 8.6 & 0.960 & 0.978 \\
\hline & *301 & 67.3 & 20.3 & 53.9 & 43.6 & 0.745 & 0.648 & 16.5 & 15.2 & 0.920 & 0.931 \\
\hline & 401 & 24.9 & 10.0 & 19.5 & 16.2 & 0.728 & 0.652 & 12.9 & 9.4 & 0.950 & 0.974 \\
\hline & 399 & 50.0 & 20.0 & 40.3 & 33.9 & 0.750 & 0.678 & 10.1 & 8.5 & 0.969 & 0.978 \\
\hline & 501 & 19.9 & 10.0 & 16.3 & 13.5 & 0.763 & 0.677 & 14.4 & 10.4 & 0.938 & 0.968 \\
\hline & 501 & 40.6 & 20.3 & 32.8 & 28.1 & 0.752 & 0.692 & 12.0 & 10.4 & 0.957 & 0.968 \\
\hline \multirow{13}{*}{ 457Mv2 } & 202 & 49.1 & 9.9 & - & 30.9 & - & 0.630 & - & 13.6 & - & 0.945 \\
\hline & *200 & 99.8 & 20.0 & - & 69.5 & - & 0.696 & - & 24.7 & - & 0.825 \\
\hline & 250 & 80.2 & 20.1 & - & 52.1 & - & 0.649 & - & 15.7 & - & 0.927 \\
\hline & 250 & 99.8 & 25.0 & - & 65.8 & - & 0.659 & - & 17.6 & - & 0.909 \\
\hline & 301 & 66.4 & 20.0 & - & 41.7 & - & 0.628 & - & 12.5 & - & 0.953 \\
\hline & 300 & 99.8 & 29.9 & - & 67.0 & - & 0.671 & - & 16.1 & - & 0.923 \\
\hline & 400 & 49.7 & 19.9 & - & 33.0 & - & 0.664 & - & 11.4 & - & 0.961 \\
\hline & 400 & 74.8 & 29.9 & - & 50.4 & - & 0.674 & - & 12.5 & - & 0.953 \\
\hline & 401 & 98.2 & 39.4 & - & 59.6 & - & 0.607 & - & 10.9 & - & 0.964 \\
\hline & 501 & 40.5 & 20.3 & - & 28.8 & - & 0.710 & - & 12.7 & - & 0.952 \\
\hline & 500 & 60.1 & 30.1 & - & 39.9 & - & 0.665 & - & 10.6 & - & 0.966 \\
\hline & 501 & 79.7 & 39.9 & - & 50.3 & - & 0.631 & - & 11.7 & - & 0.959 \\
\hline & 501 & 101.1 & 50.7 & - & 74.5 & - & 0.737 & - & - & - & - \\
\hline
\end{tabular}

Table 3. Summary of beam current and divergence angle for two different threshold-based limits.

American Institute of Aeronautics and Astronautics 


\section{Self-Consistency of the Iterative Pathfinding Method}

To determine the validity of the iterative pathfinding method, this study will look at the self-consistency of the method and comparison to far-field Faraday probe results, which is in the next sub-section. The sensitivity study was performed by varying the limits of integration over a range of values and seeing how the analysis method responded. As previously mentioned, the current convergence algorithm became unstable at very low values of the threshold fraction. Non-convergent results will not be shown. Since the iterative pathfinding method was devised to tackle the issue of calculating point of origin and divergence angle, the divergence angle will be the primary metric of self-consistency.

Figure 13 shows the divergence angle calculated by the iterative pathfinding method as a function of threshold fraction for four cases of the $300 \mathrm{M}$. All seven cases displayed similar behavior but some were not plotted to avoid clutter. In general, the divergence angle was found to be within $\pm 2^{\circ}$ of the mean over a fairly large range of the threshold fraction. The ability of the iterative pathfinding method to determine angles appeared to be self-consistent.

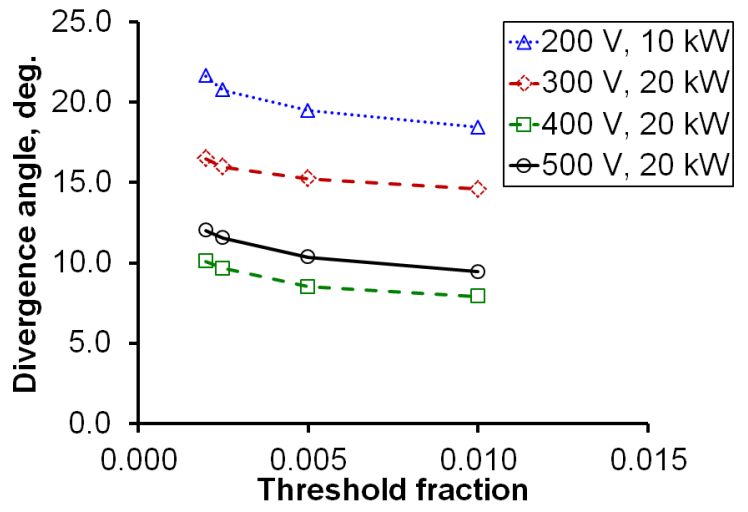

Figure 13. Sensitivity study of the divergence angle versus the threshold fraction for several operating conditions of the $300 \mathrm{M}$.

\section{E. Comparison with Farfield Faraday Probe Data}

Comparison between near-field and far-field Faraday probe data is carried out using data sets from the NASA300M. The far-field Faraday probe data were obtained using polar sweeps at a distance of 5 mean channel diameters away from the thruster. CEX ions in the wings of the sweeps were removed by performing exponential curve-fits from $10^{\circ}$ out to $25^{\circ}$ and then extrapolating to $90^{\circ} .{ }^{22}$ SEE effects had been corrected from the results.

Table 4 compares the results of near-field Faraday probe analysis to far-field Faraday probe analysis. The threshold fraction for this set of near-field Faraday probe results is $0.2 \%$. While performing the sensitivity analysis, the authors note that a threshold fraction of $0.2 \%$ also yield a very good agreement on the total beam current, in addition to being the lowest fraction for which applying the iterative pathfinding method on the $300 \mathrm{M}$ data would converge. This trend is likely a coincidence as it does not hold true for the $457 \mathrm{Mv} 2$ data. From Table 4 one can see the good agreement in total ion current between using the near-field Faraday probe data and the far-field Faraday probe data, which leads to very similar current utilization efficiencies. The calculated divergence angles are generally lower for the near-field Faraday probe data, which leads to higher divergence efficiencies. As result, the products of the two efficiency factors are higher for the near-field results but only by $\sim 5 \%$. The results in Table 4 suggests that applying iterative pathfinding method to near-field Faraday probe data is generating the same trends and very similar values as the far-field Faraday probe analysis method.

One way to interpret the similarity between the near-field and far-field Faraday probe results is that the far-field

Table 4. Comparison between near-field and far-field Faraday probe analysis for the NASA-300M.

\begin{tabular}{|c|c|c|c|c|c|c|c|c|c|c|c|c|}
\hline \multirow{2}{*}{ 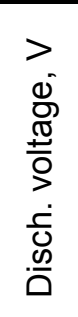 } & \multirow{2}{*}{ 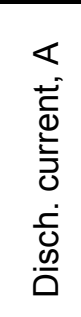 } & \multirow{2}{*}{ 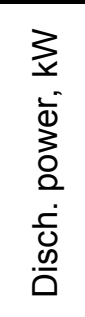 } & \multicolumn{2}{|c|}{$\begin{array}{c}\text { Total beam } \\
\text { current, } A \\
\text { (Corrected } \\
\text { for SEE) } \\
\end{array}$} & \multicolumn{2}{|c|}{$\eta_{\mathrm{b}}$} & \multicolumn{2}{|c|}{$\begin{array}{l}\text { Divergence } \\
\text { angle, deg. }\end{array}$} & \multicolumn{2}{|c|}{$\eta_{d}$} & \multicolumn{2}{|c|}{$\eta_{\mathrm{b}}{ }^{*} \eta_{\mathrm{d}}$} \\
\hline & & & $\mathrm{NF}$ & FF & $\mathrm{NF}$ & FF & NF & FF & $\mathrm{NF}$ & FF & $\mathrm{NF}$ & FF \\
\hline 200 & 50.3 & 10.1 & 40.5 & 40.1 & 0.806 & 0.806 & 21.6 & 26.3 & 0.864 & 0.804 & 0.697 & 0.648 \\
\hline 300 & 33.3 & 10.0 & 26.4 & 25.7 & 0.793 & 0.766 & 11.6 & 15.1 & 0.960 & 0.932 & 0.761 & 0.714 \\
\hline 301 & 67.3 & 20.3 & 53.9 & 52.6 & 0.801 & 0.776 & 16.5 & 20.4 & 0.920 & 0.878 & 0.736 & 0.681 \\
\hline 401 & 24.9 & 10.0 & 19.5 & 19.7 & 0.783 & 0.777 & 12.9 & 14.9 & 0.950 & 0.934 & 0.744 & 0.726 \\
\hline 399 & 50.0 & 20.0 & 40.3 & 38.2 & 0.807 & 0.768 & 10.1 & 14.4 & 0.969 & 0.938 & 0.782 & 0.720 \\
\hline 501 & 19.9 & 10.0 & 16.3 & 16.1 & 0.820 & 0.795 & 14.4 & 15.3 & 0.938 & 0.930 & 0.769 & 0.740 \\
\hline 501 & 40.6 & 20.3 & 32.8 & 31.4 & 0.808 & 0.780 & 12.0 & 14.7 & 0.957 & 0.936 & 0.773 & 0.729 \\
\hline
\end{tabular}

American Institute of Aeronautics and Astronautics 
plume is simply a super-positioning of the near-field plasma jets. This interpretation is in agreement with the meanfree-path calculated from the plasma density in the transition region $(0.5<\mathrm{Z}<5)$. On the other hand, one can also interpret the small difference between the near-field and far-field Faraday probe results to be a sign of plumemerging action. If one take the jets from the two sides of the thruster and intersect them, one would expect some level of scattering, which increases plume divergence. On the average, the plume divergence angle found in the farfield was $3^{\circ}$ higher than in the near-field, which may reflect the scattering effect.

The results in Table 4 also bring up a previously mentioned issue for near-field Faraday probe analysis. While the total beam current calculated from near-field and far-field data agrees well, the values can be tweaked by adjusting the threshold fraction. For example, decreasing the threshold fraction (assuming convergence is still achieved) would extend the integration domain, increase the total beam current, and increase the divergence angle. The problem is that there is no physical justification for selecting any given value of the threshold fraction other than to match far-field Faraday probe data. Thus, the value of a near-field Faraday probe for engineering analysis of a Hall thruster is unclear when a far-field Faraday probe gives less ambiguous results and is generally easier to implement. However, near-field Faraday probe was originally designed for scientific studies of the evolution of the near-field plume and appears well suited for that purpose. The near-field Faraday probe is able to map out Hall thruster plasma structures that are otherwise undetectable. The observation earlier in the paper on "anomalous" plasma plume downstream of the cathode is one example of how the near-field Faraday probe can help Hall thruster researchers discover new phenomena in the near-field region.

\section{Summary and Future Works}

A new analysis method, called iterative pathfinding, had been devised for analyzing near-field Faraday probe data. Unlike most previous methods, the iterative pathfinding method relies on the properties of the plasma to determine the location of the point of origin, from which travel and divergence angles of the plasma jet can be calculated. The iterative pathfinding method was applied, after removal of the cathode plume, with threshold-based integration limits. Sensitivity analysis of the divergence angle results over a range of threshold fraction showed that method is self-consistent. Comparison of the near-field Faraday probe results to far-field Faraday probe results for the $300 \mathrm{M}$ showed good agreement. The total beam current calculated from the two sets of data agreed when a threshold fraction of 0.002 is selected. At the same threshold fraction, the divergence angle found in the near-field was on the average $3^{\circ}$ lower than in the far-field. The difference in divergence angle could be a result of ion scattering in the transition region between near-field and far-field. However, the authors noted that the choice of integration limit can affect the near-field Faraday probe results, particularly the total beam current.

A method for removing the plume of a centrally-mounted cathode from the near-field Faraday probe data was also tested. A dense plasma plume was observed downstream of the cathode along the thruster central axis even after applying cathode plume removal for operating conditions with high discharge current. Several possible explanations were proposed though none could be confirmed or denied in this study.

The next step to improve the iterative pathfinding method is to refine the convergence algorithm. The goal is to improve the method to the point where it can be applied to various data sets, even ones with a lot noise. Another important next-step is to, if possible, devise a mean of overcoming the ad hoc way in which integration limits are set. 


\section{Acknowledgments}

We thank the NASA Space Technology Mission Directorate In-Space Propulsion project for funding the initial work to obtain the near-field Faraday probe data from the NASA-300M and NASA-457Mv2. We thank Timothy D. Smith for managing this project.

\section{References}

${ }^{1}$ Finley, C. J. and Peck, N., "TacSat-2: A Story of Survival", Proceedings of the AIAA/USU Conference on Small Satellites, SSC07-VII-2, http://digitalcommons.usu.edu/smallsat/2007/all2007/44/, Utah State University, 2007.

${ }^{2}$ de Grys, K., Mathers, A., Welander, B., and Khayms, V., "Demonstration of 10,400 Hours of Operation on a $4.5 \mathrm{~kW}$ Qualification Model Hall Thruster", 46th AIAA/ASME/SAE/ASEE Joint Propulsion Conference \& Exhibit, AIAA-2010-6698, Nashville, TN, 25-28, Jul., 2010.

3"NASA Exploration Systems Mission Directorate Presentation, Human Space Exploration Summary", http://www.nasa.gov/exploration/new space enterprise/home/heft summary.html, Jan., 2011.

${ }^{4}$ Mercer, C. R., et al., "Benefits of Power and Propulsion Technology for a Piloted Electric Vehicle to an Asteroid ", 47th AIAA/ASME/SAE/ASEE Joint Propulsion Conference \& Exhibit, AIAA-2011-7252, San Diego, CA, 31 Jul.- 3 Aug., 2011.

${ }^{5}$ Haas, J. M., Gallimore, A. D., McFall, K., and Spanjers, G., "Development of a high-speed, reciprocating electrostatic probe system for Hall thruster interrogation", Review of Scientific Instruments, Vol. 71, No. 11, doi:10.1063/1.1318921, Nov., 2000, pp. 4131-4138.

${ }^{6}$ Haas, J. M. and Gallimore, A. D., "Internal Plasma Potential Profiles in a Laboratory-Model Hall Thruster", Physics of Plasmas, Vol. 8, No. 2, doi:10.1063/1.1338535, Feb., 2001, pp. 652-660.

${ }^{7}$ Hofer, R. R. and Gallimore, A. D., "Recent Results from Internal and Very-Near-Field Plasma Diagnostics of a High Specific Impulse Hall Thruster", 28th International Electric Propulsion Conference, IEPC-2003-037, Toulouse, France, Mar., 2003.

${ }^{8}$ Reid, B. M., "The Influence of Neutral Flow Rate in the Operation of Hall Thrusters", Ph.D. Dissertation, Aerospace Engineering, University of Michigan, Ann Arbor, MI, 2008.

${ }^{9}$ Jameson, K. K., "Investigation of Hollow Cathode Effects on Total Thruster Efficiency in a 6 kW Hall Thruster", Ph.D. Dissertation, Aerospace Engineering, University of California, Los Angeles, Los Angeles, CA, 2008.

${ }^{10}$ Herman, D. A., Shastry, R., Huang, W., Soulas, G. C., and Kamhawi, H., "Plasma Potential and Langmuir Probe Measurements in the Near-field Plume of the NASA 300M Hall Thruster", 48th AIAA/ASME/SAE/ASEE Joint Propulsion Conference \& Exhibit, AIAA-2012-4115, Atlanta, GA, 29 Jul.- 1 Aug., 2012.

${ }^{11}$ Huang, W., Shastry, R., Herman, D. A., Soulas, G. C., and Kamhawi, H., "Ion Current Density Study of the NASA-300M and NASA-457Mv2 Hall Thrusters", 48th AIAA/ASME/SAE/ASEE Joint Propulsion Conference \& Exhibit, AIAA-2012-3870, Atlanta, GA, 29 Jul.- 1 Aug., 2012.

${ }^{12}$ Shastry, R., Huang, W., Herman, D. A., Soulas, G. C., and Kamhawi, H., "Plasma Potential and Langmuir Probe Measurements in the Near-field Plume of the NASA 457Mv2 Hall Thruster", 48th AIAA/ASME/SAE/ASEE Joint Propulsion Conference \& Exhibit, AIAA-2012-4196, Atlanta, GA, 29 Jul.- 1 Aug., 2012.

${ }^{13}$ Shastry, R., "Experimental Characterization of the Near-Wall Region in Hall Thrusters and its Implications on Performance and Lifetime", Ph.D. Dissertation, Aerospace Engineering, University of Michigan, Ann Arbor, MI, 2011.

${ }^{14}$ Hofer, R. R., Goebel, D. M., Mikellides, I. G., and Katz, I., "Design of a Laboratory Hall Thruster with Magnetically Shielded Channel Walls, Phase II: Experiments", 48th AIAA/ASME/SAE/ASEE Joint Propulsion Conference \& Exhibit, AIAA-2012-3788, Atlanta, GA, 29 Jul.- 1 Aug., 2012.

${ }^{15}$ Reid, B. M. and Gallimore, A. D., "Plasma Potential Measurements in the Discharge Channel of a 6-kW Hall Thruster", 44th AIAA/ASME/SAE/ASEE Joint Propulsion Conference \& Exhibit, AIAA-2008-5185, Hartford, CT, 21-23 Jul., 2008.

${ }^{16}$ Brown, D. L. and Gallimore, A. D., "Evaluation of Ion Collection Area in Faraday probes", Review of Scientific Instruments, Vol. 81, No. 6, doi:10.1063/1.3449541, 25 Jun., 2010, pp. 063504.

${ }^{17}$ Brown, D. L. and Gallimore, A. D., "Evaluation of Facility Effects on Ion Migration in a Hall Thruster Plume", Journal of Propulsion and Power, Vol. 27, No. 3, doi:10.2514/1.B34068, May-Jun, 2011, pp. 573-585.

${ }^{18}$ Manzella, D. M., "Scaling Hall Thrusters to High Power", Ph.D. Dissertation, Mechanical Engineering, Stanford University, Stanford, CA, 2005.

${ }^{19}$ Kamhawi, H., Haag, T. W., Jacobson, D. T., and Manzella, D. H., "Performance Evaluation of the NASA-300M 20 kW Hall Effect Thruster", 47th AIAA/ASME/SAE/ASEE Joint Propulsion Conference \& Exhibit, AIAA-2011-5521, San Diego, CA, 31 Jul.- 3 Aug., 2011.

${ }^{20}$ Hofer, R. R., Peterson, P. Y., Gallimore, A. D., and Jankovsky, R. S., "A High Specific Impulse Two-Stage Hall Thruster with Plasma Lens Focusing", 27th International Electric Propulsion Conference, IEPC-2001-036, Pasadena, CA, 15-19 Oct., 2001.

${ }^{21}$ Hofer, R. R. and Gallimore, A. D., "The Role of Magnetic Field Topography in Improving the Performance of High-Voltage Hall Thrusters", 38th AIAA/ASME/SAE/ASEE Joint Propulsion Conference \& Exhibit, AIAA-2002-4111, Indianapolis, IN, 7-10 Jul., 2002.

${ }^{22}$ Huang, W., Shastry, R., Soulas, G. C., and Kamhawi, H., "Farfield Plume Measurement and Analysis on the NASA-300M", 60th Joint Army-Navy-NASA-Air Force Propulsion Meeting, Colorado Springs, CO, 29 Apr-2 May, 2013.

${ }^{23}$ Hagstrum, H. D., "Auger Ejection of Electrons from Molybdenum by Noble Gas Ions", Physical Review, Vol. 104, No. 3, doi:10.1103/PhysRev.104.672, 1 Nov., 1956, pp. 672-683. 
${ }^{24}$ Hagstrum, H. D., "Auger Ejection of Electrons from Tungsten by Noble Gas Ions", Physical Review, Vol. 96, No. 2, doi:10.1103/PhysRev.96.325, 15 Oct., 1954, pp. 325-335.

${ }^{25}$ Huang, W., Kamhawi, H., and Shastry, R., "Farfield Ion Current Density Measurements before and after the NASA HiVHAc EDU2 Vibration Test", 48th AIAA/ASME/SAE/ASEE Joint Propulsion Conference \& Exhibit, AIAA-2012-4195, Atlanta, GA, 29 Jul.- 1 Aug., 2012.

${ }^{26}$ Reid, B. M. and Gallimore, A. D., "Near-field Ion Current Density Measurements of a 6-kW Hall Thruster", 31st International Electric Propulsion Conference, 2009-124, Ann Arbor, MI, 20-24 Sep., 2009.

${ }^{27}$ Hagstrum, H. D., "Auger Ejection of Electrons from Tungsten by Noble Gas Ions", Physical Review, Vol. 104, No. 2, doi:10.1103/PhysRev.104.317, 15 Oct., 1956, pp. 317-318.

${ }^{28} \mathrm{Kim}, \mathrm{V}$. , "Main physical features and processes determining the performance of stationary plasma thrusters", Journal of Propulsion and Power, Vol. 14, No. 5, 1998, pp. 736-743.

${ }^{29}$ Hofer, R. R., "Development and Characterization of High-Efficiency, High-Specific Impulse Xenon Hall Thrusters", Ph.D. Dissertation, Aerospace Engineering, University of Michigan, Ann Arbor, MI, 2004.

${ }^{30}$ Brown, D. L., "Investigation of Flow Discharge Voltage Hall Thruster Characteristics and Evaluation of Loss Mechanisms", Ph.D. Dissertation, Aerospace Engineering, University of Michigan, Ann Arbor, MI, 2009. 